\title{
THE RELATIONSHIP OF BIRTH ORDER AND SOCIOECONOMIC STATUS \\ TO THE CREATIVITY OF PRESCHOOL CHILDREN
}

$$
\text { by }
$$

\author{
Joanne Sally Lichtenwalner \\ Thesis submitted to the Graduate Faculty of the \\ Virginia Polytechnic Institute \\ in partial fulfillment for the degree of \\ MASTER OF SCIENCE
}

in

Child Development

APPROVED :

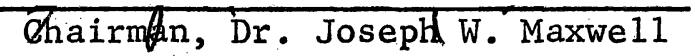

D7. James E. Montgomelpy, Head

Dr. Shirley C. Farrier

Department of Management,

Housing and Family Development

November 1968

Blacksburg, Virginia 
ACKNOWLEDGEMENTS . . . . . . . . . . . . . . . . iv LIST OF TABLES. • • • . . . . . . . . . . . . . . v v IIST OF FIGURES . . . . . . . . . . . . . . . . . . vi vi CHAPTER

I. INTRODUCTION. . . . . . . . . . . . . . 1

Purpose. . . . . . . . . . . . . . . . 3

Hypotheses . . . . . . . . . . . . . 3

II. REVIEW OF LITERATURE. • . . . . . . . . . . . . 5

Nature and Measurement of Creativity . . . . . 5

Creativity and I.Q................... 7

Ordinal Position and Creativity. . . . . . . . 9

Authority and Creativity . . . . . . . . . . 14

Socioeconomic Status and Creativity. . . . . . . 15

III. PROCEDURE . . . . . . . . . . . . . . . 19

Description of Subjects. . . . . . . . . . . 19

Instrument . . . . . . . . . . . . . 20

Collection of Data ................. 21

Analysis of Data . . . . . . . . . . 25

IV. RESULTS AND DISCUSSION . . . . . . . . . . . . 26

Results. . . . . . . . . . . 26

Discussion . . . . . . . . . . . . 42

Limitations and Recommendations. . . . . . . . 45 
Page

V. SUMMARY . . . . . . . . . . . . . . . . . 48

REFERENCES. . . . . . . . . . . . . . . . . 52

APPENDIX. . . . . . . . . . . . . . . . . . 56

VITA. . . . . . . . . . . . . . . . . . . 65 
The author especially wishes to express her deepest gratitude to Dr. Joseph W. Maxwe11, her major advisor, for his invaluable assistance throughout this research project. Largely due to his guidance, inspiration and encouragement, this study has been a valuable and rewarding first experience at research for the author.

Appreciation is also expressed to the members of the supervisory committee, Dr. James E. Montgomery, Dr. Shirley Farrier, Miss Azalee Kimbrell, and Dr. Esther A. Martin for their critical reading of the manuscript and helpful suggestions.

Sincere appreciation is extended to all the directors and teachers of the University Nursery School, the Methodist Nursery School and Kindergarten, The Mt. Tabor Day Care Center, the Floyd Day Care Center, and the Lansdowne, Loudon and St. John Total Action Against Poverty Day Care Centers, all in Southwestern Virginia, for their cooperation in allowing children enrolled in their schools to be used as subjects for this study. The writer is also indebted to the preschool children who participated in this research.

The writer expresses special thanks to her husband for his everpresent strength and encouragement. 
1. Distribution by Sex, Ordinal Position, and Socioeconomic Status. . . . . . . . . . . . 20

2. Differences in Originality Scores of Preschool Children by Ordinal Position. . . . . . . . . . . 27

3. Differences in Originality Scores of Preschool Children by Sex and Ordinal Position . . . . . . . . . . 29

4. Differences in Originality Scores of Preschool Children

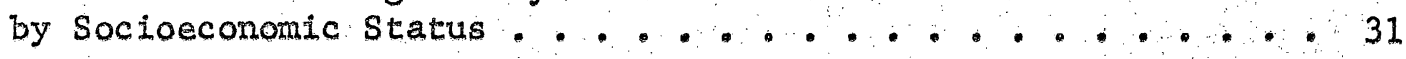

5. Differences in Originality Scores of Preschool Children by Sex and Socioeconomic Status . . . . . . . . 34

6. Differences in Originality Scores of Preschool Children

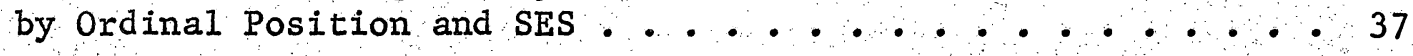




\section{LIST OF FIGURES}

Page

1.. Distribution of Originality Scores by Ordinal Position. . . . 30

2. Distribution of Originality Scores by Sex and Ordinal Position. . . . . . . . . . . . . . . 33

3. Distribution of Originality Scores by Socioeconomic Status. - 35

4. Distribution of Originality Scores by Sex and Socioeconomic Status..................... 38

5. Distribution of Originality Scores by Ordinal Position and Socioeconomic Status. . . . . . . . . . . 41 


\section{CHAPTER I}

\section{INTRODUCTION}

Creativity, the ability to produce something new, unique or original, is a relatively new field of research. Little investigation was done before 1950 when Guilford (1950) spoke of the appalling neglect of creativity by psychologists. Subsequently Guilford developed two concepts which have been useful in studying creativity: divergent and convergent thinking (Eisner, 1963). Divergent thinking, which most characterizes creativity, is speculative thinking which departs from information already possessed (Eisner, 1963; Lewis, 1965). The I.Q. score, as it is now obtained, measures expected or convergent thinking and is not a reliable predictor of creativity (Getzels and Jackson, 1962). Among the nearly 60 dimensions of the mind discovered to date, more than 50 are nonintellectual in nature (C. W. Taylor, 1961) and can not be measured by standard I.Q. tests.

Although little is known about the growth of creativity, many educators believe that creativity in children is too often stifled before it has a chance to develop. Highly creative behavior is unrewarded by teachers and peers who are more comfortable with highly intelligent students than highly creative students (Mukerji, 1965; Getzels and Jackson, 1962). The beneficial aspects of spontaneous creativity in young children has been greatly neglected. The person whose response is original, inventive, and atypical is extremely 
important socially, because progress takes place through constructive variations from the accepted, the conventional, and the routine.

Theoretically, the study of the development of creative ability should begin with the study of the infant; however, the complex and elusive quality of creativity has made such an approach impractical (Starkweather, 1964). Instead, much of the recent research has been devoted to the study of highly creative adults, usually identified as creative by their products or their work. The personalities of these adults have been studied in attempts to identify the various characteristics which are factors in, or which may be necessary for, the expression of creativity. Studies of adolescents and school-age children have followed. However, study of creative ability in children of preschool age has been extremely limited, seemingly through neglect or lack of suitable criteria for measuring creativity in young children.

One problem which must be taken into consideration when studying the creative ability of preschool children is whether creative potential can be identified before there has been creative achievement. Starkweather (1965) concluded that the potentially creative preschool child cannot be identified by his product as an artist or inventor can, but that he may be identified by certain personality characteristics such as originality and curiosity. This leads to the possibility that factors which affect the development of personality may also affect the development of creativity. A child's ordinal position in a family is believed to influence his personality (Adler, 1927, 1930; Hurlock, 1964; Hoffman and Hoffman, 1966). The factors generated by birth order which influence personality development may also affect the development of creativity in a child. 
Punishment and ridicule are the two greatest deterrents to creative activity (Bossard, 1962; Rogers, 1960). Children from authoritative, harsh environments may be less creative than children from more favorable or permissive environments. Social class may be an influencing factor in the development of creativity because, in general, lower class parents are more authoritarian in child-rearing practices than middle class parents (Smith, 1965; Bayley and Schaffer, 1960; Sears et. al., 1957, Waters and Crandal1, 1964). Therefore, it may well be that the socioeconomic status of the family into which a child is born will have some influence on the amount of creativity which he develops. However, to date no research has been done to compare the effects of different socioeconomic classes on the development of creativity.

\section{$\underline{\text { Purpose }}$}

The purpose of this research was to study the effects which birth order and socioeconomic class have on creativity expressed by preschool children by:

1. comparing the creativity of preschool children from the lower class with preschool children from the middle socioeconomic class.

2. comparing the creativity of first-born and only children with later-born children.

\section{Hypotheses}

Specifically', the following nul.1. hypotheses were tested:

1. There is no significant relationship between ordinal position and 
originality of preschool children. First-born or only children and later-born children will be equally original.

2. There is no significant relationship between socioeconomic status and originality of preschool children. Lower-class and middleclass children will be equally original. 


\section{REVIEW OF LITERATURE}

\section{Nature and Measurement of Creativity}

Carl Rogers (1960). defined the creative process as "...the emergence in action of a novel relational product, growing out of the uniqueness of the individual on the one hand, and the materials, events, people, or circumstances of his life on the other."

As reported by Eisner (1963), several important assumptions underlie the work of psychologists who study creativity: (1) creativity is a capacity possessed in some degree by everyone, (2) creativity for the researcher must be public in that it must be able to be observed, and (3) creativity is measurable.

Torrance (1959) urged parents of creative children:

...to recognize that everyone possesses to some degree the ability involved in being creative, that these abilities can be increased or decreased by the way children are treated, and that it is a legitimate function of the home and the school to provide the experiences and the guidance which.will free them to develop and function fully.

Psychologists have developed many tests of creative thinking to identify the creative personality. Torrance (1959), who has studied creativity of elementary school children, used such devices as the Askand-Guess Test, Product Improvement Task, Imaginative Stories about Divergent Animals and People, Just Suppose Test, Incomplete Figures, Circles and Squares, Picture Construction, and depth interviews. 
Starkweather (1965), who has studied the creative ability of preschool children, said:

..one can speculate that to be creative, an individual must be relatively free from inhibition, free to make novel combinations of ideas, and free to express his curiosity and imagination; he must be willing to try difficult tasks and willing to be a nonconformist.

Consequently, she has been developing tests for preschool children which measure four aspects of creativity: conformity-nonconformity, willingness to try difficult tasks, originality, and curiosity or preference for the novel. In all of her work she is seeking to develop instruments which are game-like and which permit the child to make a simple behavioral response which will reveal the particular characteristic in which she is interested.

Guilford (1959b) presented three ways to measure the trait of originality: counting the number of responses that are judged to be clever, utilizing items calling for remote associations, and weighing the subject's responses in proportion to their infrequency of occurrence in a population of subjects. Guilford (1957) stated that subjects with higher originality scores were more interested in esthetic expression, reflective and divergent thinking, more tolerant of ambiguity, and felt less need for orderliness.

Barron (1955) hypothesized that if some persons are regularly original while others are regularly unoriginal, it must be that certain patterns of relatively enduring traits either facilitate or impede the production of original activities. He distinguished the original from the unoriginal persons among captains in the United States Air Force, then compared the two groups for personality traits. Originality was 
found to be related to independence of judgment, to personal complexity, to self-assertion and dominance, and finally to the rejection of suppression as a mechanism for the control of impulse.

Lowenfeld (1958) summarized the basic findings of seven years of research on creativity by the Department of Art Education of the Pennsylvania State University. Eight criteria of creativity which differentiate between creative and non-or less-creative people were reported: (1) sensitivity to problems; (2) fluency of ideas; (3) flexibility; (4) originality; (5) redefinition and the ability to rearrange; (6) analysis or the ability to abstract; (7) synthesis and closure, that is, the combining of several elements to form a new whole, and (8) coherence of organization.

\section{Creativity and I.Q.}

In a review of literature Taylor and Holland (1962) found the majority of studies suggested that the correlation of intelligence tests or components of intelligence tests to creative performance is. generally low in unselected populations and is zero and even negative for homogenous samples at high levels of intelligence. The best conclusion at present is that intelligence, as now measured, accounts for only a minor portion of the variation in creative performance and, by itself, is by no means an adequate measure of creativity. In fact, nearly all research that attempts to measure and study creativity has focused on nonintellectual tests, biographical inventories, and environmental factors. 
Bossard (1962) stated:

I.Q. tests measure only a few of the mental abilities and appeal to particular types of individuals: children who accept yes - no, right - wrong question situations, those who can memorize considerable amounts of culturally approved data, and those who might be motivated by a desire to ingratiate themselves with authorities. I.Q. tests don't measure the child's flexibility, originality ... and depth of thinking or intuition.

According to Lewis (1965), the I.Q. score, as it is now procured, measures expected or convergent thinking, whereas, creativity is most characterized by divergent thinking (Eisner, 1963). Getzels and Jackson (1962) found that intelligence was far from a reliable predictor of creativity. Eisner (1963) asserted that the distinction between creativity and intelligence is artificial. He said that the seeming separation between these concepts is due to a too narrowly conceived concept of intelligence.

Guilford (1959) suggested that some components of memory, cognition, evaluation, convergent production, and especially divergent production are involved in creative work. More specifically, the highlevel aptitude factors most involved are probably originality, adaptive flexibility, spontaneous flexibility, ideational fluency, expressional fluency, associational fluency, word fluency, sensitivity to problems, visualization, judgment, and redefinition.

Werner (1964) compared the top $20 \%$ of highly intelligent children with the top $20 \%$ of highly creative children from five nursery and elementary schools and two high schools in Minneapolis and Chicago. Five major nonintellectual factors differentiated the highly creative from the highly intelligent and have also been found to distinguish 
creative adults: (1) a sense of humor; (2) the co-existence of both masculine and feminine traits, such as sensitivity and independence; (3) a preference for self-initiated play and work; (4) a willingness to take risks; (5) a family setting which is non-conventional characterized by open and not always calm expression of strong feeling, less vigilant supervision by the parents, less stress on conventional virtues and values, and a not overly close family unit. The overall impression of families of children with high I.Q.'s was that, on the whole, things were planned for and risks taken were minimal. The overall impression of the families of highly creative children was that risks were accepted and even sought.

Torrance (Mukerji, 1965) stated:

From the best research evidence available and the observation of many investigators, creative imagination during early childhood seems to reach a peak between 4 and $4 \frac{1}{2}$ years and is followed by a drop at about age five when the child enters school for the first time. There are now indications, however that this drop in five-year-olds is man-made or cultural rather than a natural phenomenon.

Getzels and Jackson (1962) found that teachers prefer high I.Q. students to highly creative students. Highly creative behavior is unrewarded by teachers and peers (Mukerji, 1965) and, as Bossard (1962) has noted, punishment and ridicule are the two greatest deterrents to creative activity anywhere.

\section{Ordinal Position and Creativity}

Alfred Adler (1927) originally introduced the idea that an individual's ordinal position in the family plays a significant role in personality development. A child's place in the birth order of the 
children may be an influential factor in the formulation of his lifestyle. According to Adler's theory: An eldest child must make an effort to remain first. He is generally conventional, dependable, and authoritative. He seems to have a high evaluation of power and is markedly conservative. The second-born child is constantly under strain, striving to catch up with the oldest. He is usually the one to oppose authority. The middle child has neither the superior position of the eldest or the youngest, and must push his way to a more favorable spot. The youngest may perceive himself to be the most disadvantaged because all the other children have a head start. He may become determined to outdistance them all. However, the youngest is also the most likely to be pampered and overindulged by his parents and may decide that it is more advantageous to remain a baby. The only child becomes dependent to a high degree, waits constantly for someone to show him the way, and searches for support at all times (Adler, 1927, 1930).

Hoffman and Hoffman (1966) maintained that every first-born child is for a time an only child, unless there are adopted children or children from another marriage. No other child is likely to receive the amount of attention, time, energy, or concern as is the first-born prior to his dethronement. But he has inexperienced parents, who are likely to be unsure of themselves and therefore less consistent and more likely to communicate their anxieties to the infanto

Hurlock (1964) reported that studies of personality and social adjustment have revealed that the oldest child is in a position which makes successful adjustment very difficult. His rather high-pitched 
relationship with his mother steadily lessens in intensity, especially when a second child arrives. Parental overprotection is likely to make the older child more conservative, less dominant and aggressive than his younger siblings. He usually lacks self-confidence and leadership qualities, is easily influenced by suggestion, is more dependent and excitable, and has his feelings hurt more easily than later-born siblings. The second-born is spared much of the parental anxiety, emotional tension, and overprotection. As a result he is usually less dependent than the first child. The mother-child relationship is warmer and more relaxed. As a rule, second-born children are less neurotic and introverted and more fun-loving and humorous than first-borns. According to Lasko (1954), parental behavior toward first children as contrasted to second-born children is, on the average, less warm emotionally and more restrictive and coercive. These differences are most apparent in the pre-school years. A similar differential exists between second and third children, but on a less distinct level。 There is evidence that parents become somewhat more consistent in their child-care practices as they gain experience with a second and third child (Lasko, 1954; Stout, 1960). A high proportion of parents have reported themselves more relaxed with later-born children than with their first-born (McArthur, 1956; R. R. Sears, 1950)。 One might expect somewhat greater permissiveness on the part of parents with their later-born children, especially in terms of tolerance of a wider range of behaviors and less readiness to invoke harsh measures of control (Hoffman and Hoffman, 1966). 
Dean (1947) investigated the personality characteristics of twenty pairs of children by having the mother make paired comparisons of her own two children on a large number of items. Children in the first ordinal position were judged by their mothers to be more dependent, more worried; more excitable, to have their feelings hurt more easily, to be less demonstratively affectionate, and to be less effective in protecting themselves from verbal or physical attack

McArthur (1956) found that first-borns are inclined to greater acceptance of conventional or adult-approved activities. He reported them to be more adult-oriented, conscientious, studious, and serious. With some consistency, mothers report the first-born to be more fearful and anxious or tense than later-born children (Macfarlane; Allen, and Honzik, 1954; P. S。 Sears, 1951).

Schachter (1959) indicated that first-born children are subjected to more inconsistent nurturance than are later-born children and consequently show more anxiety and dependency behavior in the form of affiliative responses. Thus, first-borns would be expected to be more conforming in a social situation than later-born children. This was confirmed in an experiment by Sampson (1962) on birth order and conformity of Coast Guard recruits under conditions of reward and fine, in which he found first-borns to be more conforming than later-borns. Becker and Carroll (1962), in an effort to compare ordinal position and conformity, conducted research using the Asch (1956) situation in which subjects exhibit varying degrees of conformity to a majority judgment. Forty-eight boys, 24 first-born and 24 later-born, served as subjects. The first-borns were considered the high-need Affiliation group, and 
the later-borns the low-need Affiliation group. The hypothesis that high need Affiliation and aspiration to group membership would be associated with greater conformity was supported.

In reviewing studies of the birth order of eminent men, Circirelli (1967) found the first-born son to be highly over-represented among the eminent. While many highly creative men are among the eminent, he contended that certainly eminence and creativity are not synonymous. Circirel1i-(1967) reported that another study found no relationship between the birth order of industrial chemists and ratings of their creativity made by superiors and co-workers. Kock (1955) found a teacher rating of originality to be unrelated to birth order among children of kindergarten age. Using the Creative Design Test, Eiseman (1964) found first-born college art students to be less original and artistically creative than the later-born students. Thus, other studies do not support the superiority of the first-born as suggested by the studies on eminence. It would seem that more information is needed to clarify the relation between birth order and creative ability (Circirel1i, 1967).

The accumulation of findings that parents of first-born and only children tend to be more anxious, overprotective, restrictive and coercive with first-born and only children than with later-born children would suggest that first-born and only children would be less creative than later-born siblings. This seems to be supported by the literature that reports first-born children to be more dependent, adult-oriented, serious, and conforming than later-born childxen. Later-born children, spared much of this parental anxiety and overprotection, are exposed to a warmer 
more relaxed atmosphere and are reported to be more independent, funloving, and extroverted than first-born children. Therefore, it would appear that later-born children are in a more favorable position for the development of creativity.

\section{Authority and Creativity}

The view that adult authority has inhibiting effects on the child is promoted today by articulate spokesmen in the fields of education and child rearing (Goodman, 1964; Maslow, 1954; Nei11, 1964; Rogers, 1960). The nonpermissive parent, even when exerting rational authority and encouraging the child to make many of his own decisions, is trying to obtain from the child conformity with parental standards. The parent who exerts authoritative control, even if it is hoped that as the child grows older control will gradually be relinquished, does indeed exert vigorous efforts to shape the child's behavior in his early years. According to Baumrind (1966), although the child may argue and test the limits, he is fundamentally satisfied with his relationship to his parents and does not revolt.

In one of a series of provocative studies, Bing (1963) concluded:

The findings led to the general conclusion that discrepant verbal ability is fostered by a close relationship with a demanding and somewhat intrusive mother, while discrepant nonverbal abilities are enhanced by allowing the child a considerable degree of freedom to experiment on his own.

Along similar lines, Getzels and Jackson (1961) found that parents of children whose I.Q. scores were high but not their creativity scores, when compared to parents of children whose creativity scores were high but not their I.Q. scores, were more authoritative in their discipline 
and more concerned about intellectual and social achievement than about inner life. Firm, intrusive parents may inhibit nonverbal achievement and enhance achievement in verbal axeas.

Nichols (1964) conducted a study to test the hypothesis that restrictive, controlling attitudes on the part of the mother are negatively related to originality and creativity of the child. Creativity was assumed to be inhibited by external control and coercion and to be fostered by permissiveness and psychological freedom. Thus, adolescents whose mothers express favorable attitudes toward authoritarian and coercive childrearing practices should score lower on personality measures of originality than those whose mothers favor less controlling childrearing practices. The subjects were 796 male and ,450 female National Merit Scholarship Award finalists and their mothers. The hypothesis that restrictive, controlling parental attitudes inhibit creativity was supported by the data. The finding that the children of authoritarian mothers obtained better grades in school and more favorable ratings by their teachers is not inconsistent with the assumption that authoritarian childrearing practices lead to conformity and "good" behavior, but stifle originality. On the basis of findings in his study, Nichols (1964) predicted that mothers in lower educational levels would be expected to have more authoritarian attitudes and therefore might also be expected to have the less creative children.

\section{Socioeconomic Status and Creativity}

Students of child development seem fairly well agreed that there are differences between middle-class and working-class mothers in their 
maternal practices and objectives (Prothro, 1966). Reviews (Bronfenbrenner, 1958; Clausen and Williams, 1963) have indicated that in the 1950's middle-class mothers in the United States differed from their lower-class counterparts in being more permissive in their treatment of infants and of young children as well as more demanding of independence and achievement of the growing child.

Research findings over the past 25 years show parents in the middle-class to be more accepting and equalitarian in their relationship to the child than parents in the lower-class (Rosen, 1964). Middleclass parents are more tolerant of the child's needs and impulses; they are more likely to take into account his intent and motives when transgressions occur than lower-class parents, who tend to respond to the immediate consequences of the child's actions (Kohn, 1959). In disciplining the child, middle-class parents more often use reasoning and appeals to guilt, and are somewhat less likely to employ physical punishment than parents in the lower-class (Sears, Maccoby, and Levin, 1957). The lower-class family system has been described as rigid and hierarchical, both as regards husband-wife and parent-child relationships (Rosen, 1964).

Waters and Crandall (1964) assessed relations between socioeconomic status and child rearing practices from 1940 to 1960. Socioeconomic status was found to be positively correlated with noncoercive maternal child rearing practices. The higher the family status, the less dictatorial were mothers' attempts to influence their children's behavior, and the less severe were their penalties for misbehaviors. Coercive maternal behavior was found to be class linked. There is 
agreement from a variety of sources (Bayley and Schaefer, 1960; Sears, Maccoby, and Levin, 1957; Kohn, 1959; Rosen, 1964; Smith, 1965) that lower-class mothers use more forceful and punitive methods of discipline than middle-class mothers.

A study by Bayley and Schaefex (1960) of the relation of socioeconomic factors to observed maternal behavior in the Berkeley Growth Study tends to confirm findings from other studies. For the total group there was a slight tendency for the mothers of higher socioeconomic status to be more warm, understanding, and accepting, and for those of lower status to be more controlling, irritable, and punitive. These tendencies were present both during the children's first three years, and later at 9 to 14 years of age. The differences were much more evident for the mothers of boys than of girls.

Smith (1965) has suggested that creative children are most often associated with an environment that emphasizes independent behavior, risk-taking, and personal judgment. In contrast, children who are not creative have been characterized as being reared in a situation which places emphasis on the safest solution. He contended that children from lower socioeconomic situations are often forced to engage in independent behavior earlier than children from middle-class circumstances. This would seem to favor the development of creativity in lower-class children. However, harsh physical punishment is observed more frequently in lower than middle socioeconomic homes, and as Bossard (1962) indicated, punishment and ridicule are the two greatest deterrents to creative activity anywhere. This would inhibit the development of creativity of lowerclass children. Yamamoto (1964) pointed to a need for more studies on 
cultural determinants of creativity, including sex stereotyping, group reaction to original members, and familial and social-class variables affecting the development of a child's creativity. 


\section{PROCEDURE}

\section{Description of Subjects}

The criteria for selection of the subjects for this study were:

1. The child must be attending a nursery school, kindergarten, or day care center in Southwestern Virginia.

2. The child must be between the ages of 4 years 0 months and 6 years 0 months at the time of testing.

3. The child must be in the lower or middle socioeconomic class as determined by the McGuire-White Index of Social Status - Short Form.

4. The child must be of the Caucasian race.

5. The child must have at least one sibling living at home with the family unless the child is an only child.

The sample consisted of 68 subjects, 36 middle-class children and 32 lower-class children. of the middle-class subjects, 18 were firstborn or only children including 9 girls and 9 boys, and 18 were laterborn children including 9 boys and 9 girls. Of the lower-class subjects, 12 were first-born or only children including 6 girls and 6 boys, and 20 were later-born children including $10 \mathrm{gir} 1 \mathrm{~s}$ and 10 boys. Table 1 shows the overall distribution of subjects by sex, ordinal position, and socioeconomic status. The children ranged in age from 4 years 1 month 
TABLE 1

Distribution by Sex, Ordinal Position, and Socioeconomic Status

\begin{tabular}{|c|c|c|c|c|c|}
\hline \multirow{2}{*}{ Ordinal Position } & \multicolumn{2}{|c|}{ Lower Class } & \multicolumn{2}{|c|}{ Middle Class } & \\
\hline & $\mathrm{M}$ & $F$ & $M$ & $\mathrm{~F}$ & Total \\
\hline oldest or only & 6 & 6 & 9 & 9 & 30 \\
\hline Later-Born & 10 & 10 & 9 & 9 & 38 \\
\hline Total & 16 & 16 & 18 & 18 & 68 \\
\hline
\end{tabular}

to 6 years 0 months at the time of testing. The average age of the total sample of children was 5 years 2 months.

The middle-class children were enrolled in the University Nursery School of Virginia Polytechnic Institute and the Methodist Nursery School and Kindergarten in Blacksburg, Virginia for an average of 8 months, 1 week. The lower-class children were enrolled in three Total Action Against Poverty Day Care Centers in Roanoke, and in addition the Floyd Day Care Center, the Mount Tabor Nursery School, and the Blacksburg Methodist Kindergarten all in Southwestern Virginia. The enrollment of the lower-class children ranged from 3 days to 1 year 9 months with an average of 8 months.

\section{Instrument}

This study was limited to one aspect of creativity: originality. The instrument used to investigate originality of preschool children was the Originality Test developed by Starkweather (n.d.) for use with children between the ages of 3 years 6 months and 6 years 6 months. The 
test is game-like, consisting of ten pairs of styrofoam objects to which the child responds when asked what they could be. Four opportunities are provided for a child to respond to each form. Each child's score is the numerical count of the number of different responses he gives. The responses are scored in the order in which the child has given them, and credit is given for each response which is different from all previous responses. The válue of the test, according to Starkweather $\left(n_{0} d_{0}\right)$, lies in its ability to identify the more original and the less original children within a given group and to compare different groups of children. Starkweather determined the reliability of the test by means of a split-half correlation using the Spearman-Brown formula. A coefficient of $+.93(p<.01)$ indicated that the test was reliable. The validity of the instrument was demonstrated by comparing teachers' judgments with children's scores. A Chi-square analysis showed agreement to be statistically significant $\left(x^{2}=22.75 ; p<.001\right)$. Inter-judge reliability in scoring using the Pearson product-moment coefficient of correlation was +.99 , significant beyond the .01 level. Additional details may be found in the Appendix.

\section{Collection of Data}

Prior to the actual collection of data, the present investigator practiced giving the test to five children not included in the sample in an effort to standardize both her verbal and physical actions during the testing situation. This was done in order to insure that each child was handled in an identical manner and that no verbal or physical cues were given to one child and not another. 
Schools in the vicinity of Blacksburg, Virginia, with kindergarten or nursery school programs were contacted by the investigator. Background information on the children was obtained from the record files in each school. In most instances, if the files were lacking in some information, the teachers were able to supply the missing data. The father's occupation, father's source of income, and father's education were needed in order to classify the children by socioeconomic status according to the McGuire-White Index of Social Status - Short Form. Children falling into the middle and lower socioeconomic classes were then divided by sex into first-born or only children and later-born children. There were a total of eight categories into which the children were classified:

1. MBO - middle class, boy, only or oldest

2. $\mathrm{MBL}$ - middle class, boy, later-born

3. MGO - middle class, girl, only or oldest

4. MGL - middle class, girl, later-born

5. LBO - lower class, boy, only or oldest

6. LBL - lower class, boy, later-born

7. LGO - lower class, girl, only or oldest

8. LGL - lower class, girl, later-born

Each child in the sample was tested individually by the investigator in an isolated room or special testing room within the school itself. In all seven schools in which children were tested, the directors and teachers were most cooperative in providing a vacant room which was suitable for testing. Each room was provided with a table and three chairs and made void of other objects which might distract a child's attention from the test. 
The investigator spent time observing in each classroom prior to the administration of the test in order to get acquainted with the children. The teachers introduced the investigator as a visitor or "Miss Joanne." Whenever possible the investigator selected those children first with whom she had already established a relationship outside of the school situation. These children had previously attended the Virginia Polytechnic Institute Nursery School in which the researcher was a graduate assistant. These children were eager to play the game and it is believed that this encouraged the other children in their classes to want to play the "game" too. The test was always referred to as a "game." In all cases after spending some time in the classroom, the investigator went directly to each subject and talked to the child about. the "game" which he might like to play. The child was then asked to accompany the investigator to the room where the "game" would be played.

Once in the room and seated the investigator showed the child the suitcase with the game in it saying, "See, there are blue things, red things, and white things in this box. First of all we are going to play with all the white ones." The investigator would then place them on the table in front of the child and encourage him to manipulate them and to talk about them asking, "Do you see any pieces that look like something to you or that you think can be made into something?" If the child did not respond, the investigator followed the directions given by Starkweather (See Appendix - Pretest or Warm-up Session). The child was praised if he was able to give at least four different ideas during the warm-up session by saying, "Good, you thought of something different for al1 these." Only two children were not able to give four different responses. In 
these two cases, each child was allowed to play with the objects, but their responses were not recorded and they were not included in the sample. According to starkweather (n.d.), the test depends on a child's ability to communicate verbally, and therefore, should not be administered to children who are unable to give four different ideas during the pretest.

After the warm-up session, the main part of the test was administered by showing the child one pair of identically shaped styrofoam pieces at a time. When he was shown the first pair, he was given his choice of the color he preferred. "Which color do you like better, red or blue?" The color the child chose was placed on the table before him and the other color was placed in front of the investigator. The child was then asked what his piece could be or what it could be made into. After he responded, he was asked what the experimenter's piece could be. Approval of each response was given by saying either "Fine," "Okay," "Al1 right," or "It certainly could be." Whether or not a child gave different responses for the various shapes, his efforts were approved in the same manner. After the child responded to all ten pairs of styrofoam objects, the entire set was presented again. However, this time the child was given the color he had not chosen and each piece was placed before the child in an alternate position, such as sideways or up-side-down. Administration of the entire test averaged about fifteen or twenty minutes for each child.

A scoring sheet was used to record each child's responses. This was held in the investigator's lap and marked as the child responded to each object. If a child inquired as to what the investigator was 
writing, or seemed concerned, she matter-of-factly told him that she played the "game" with a lot of children and that writing it down helped her remember what he said. This seemed to satisfy the few children who showed concern.

\section{Analysis of Data}

A total of 68 Originality tests were individually administered to preschool children enrolled in preschool programs. The children's responses were scored and tabulated by the investigator. The children were classified by sex, ordinal position, and socioeconomic status. Socioeconomic class position was assessed by the McGuire-White Index of Social Status - Short Form (1955).

The Mann-Whitney $U$ test was used to analyze the difference between the originality scores of preschool children in each of the following areas:

1. A comparison of boys with girls.

2. A comparison of middle-class children with lower-class children.

3. A comparison of first-born and only children with later-born children.

4. A comparison of sex and ordinal position.

5. A comparison of sex and socioeconomic status.

6. A comparison by ordinal position and socioeconomic status.

The values of $U$ and $z$ were determined by calculations described by Siegel (1956). The .05 level of significance was accepted as the criterion for rejecting null hypotheses. 


\section{CHAPTER IV}

\section{RESULTS AND DISCUSSION}

\section{Results}

Because sex may be an influencing factor, it was necessary to compare the relationship between sex and originality of preschool children in order to determine how much effect, if any, it might have on the other variables of socioeconomic status and ordinal position to be measured in this study. Therefore, the originality scores of boys and girls were compared. Table 2 presents the results of the comparison between the total sample of thirty-four boys and thirty-four girls. The mean score of the total sample of thirty-four boys was 20.56 . The mean score of the total sample of thirty-four girls was 20.53. The difference between these two groups was not statistically significant, indicating that sex was not a contaminating factor and, therefore, did not interfere with the other variables that were measured. This is in agreement with Starkweather's finding (1967) of no difference between sex and originality in a group of 80 preschool children.

The distribution of scores differed greatly. Individual scores ranged from a low of 8 to a high of 36, indicating a wide variation in the degree of originality which these preschool children possessed. This lends support to the belief that this instrument can distinguish original preschool children from less original preschool children. 


\section{TABLE 2}

Differences in Originality Scores of Preschool Children By Sex

\begin{tabular}{llllll}
\hline & $\mathrm{N}$ & Mean & SD & $\mathrm{z}$ & $\mathrm{p}$ \\
\hline & & & & & \\
\hline & & & & & \\
Boys & 34 & 20.56 & 7.87 & & \\
& & & & & \\
Girls & 34 & 20.53 & 7.90 & & \\
\hline
\end{tabular}

(Mann-Whitney U, Siegel, S. Values of z, p. 247.) 
Hypothesis 1: There is no significant relationship between ordinal position and originality of preschool children. First-born or only children and later-born children will be equally original.

In order to test this hypothesis, the originality scores for these two groups were compared. As seen in Table 3, the mean score of the total sample of oldest and only children was 22.5 , whereas the mean score of the total sample of later-born children was 19.0. This difference was significant at a confidence level of .04 , indicating that first-born and only children are more original than later-born children.

In analyzing the distribution of scores, the scores were combined into quartiles with a range of seven points in each. When grouped in this manner, the scores in the lowest quartile ranged from 8 through 15, those in the second quartile from 16 through 22, those in the third quartile from 23 through 29, and those in the highest quartile from 30 through 36. Figure 1 shows that $20.0 \%$ of the first-born and only children as compared with $10.5 \%$ of the later-born children had scores in the highest quartile. Forty-three per cent of the oldest or only children had scores between 23 and 36 in the third and fourth quartiles, but only $29 \%$ of the later-born children had scores in this same range. Thirty-four per cent of the later-born children had scores in the lowest quartile compared with only $16 \%$ of the oldest or only children. Table 4 summarizes the findings when the originality scores are grouped by both sex and ordinal position. The difference between oldest or only boys and later-born boys was not significant. No significant difference was observed when oldest or only girls were compared with 
TABLE 3

Differences in Originality Scores of Preschool Children by Ordinal Position

\begin{tabular}{lccccc}
\hline & $\mathrm{N}$ & Mean & SD & $\mathrm{z}$ & $\mathrm{p}$ \\
\hline & & & & & \\
Oldest and only & 30 & 22.47 & 8.16 & & \\
Later-born & 38 & 19.03 & 7.31 & & \\
\hline
\end{tabular}


Figure 1

Distribution of Originality Scores by Ordinal Position

$$
\begin{aligned}
& E \text { - oldest or only Children (N=3 } \\
& \square \text { - Later-Born Children }(\mathrm{N}=38)
\end{aligned}
$$

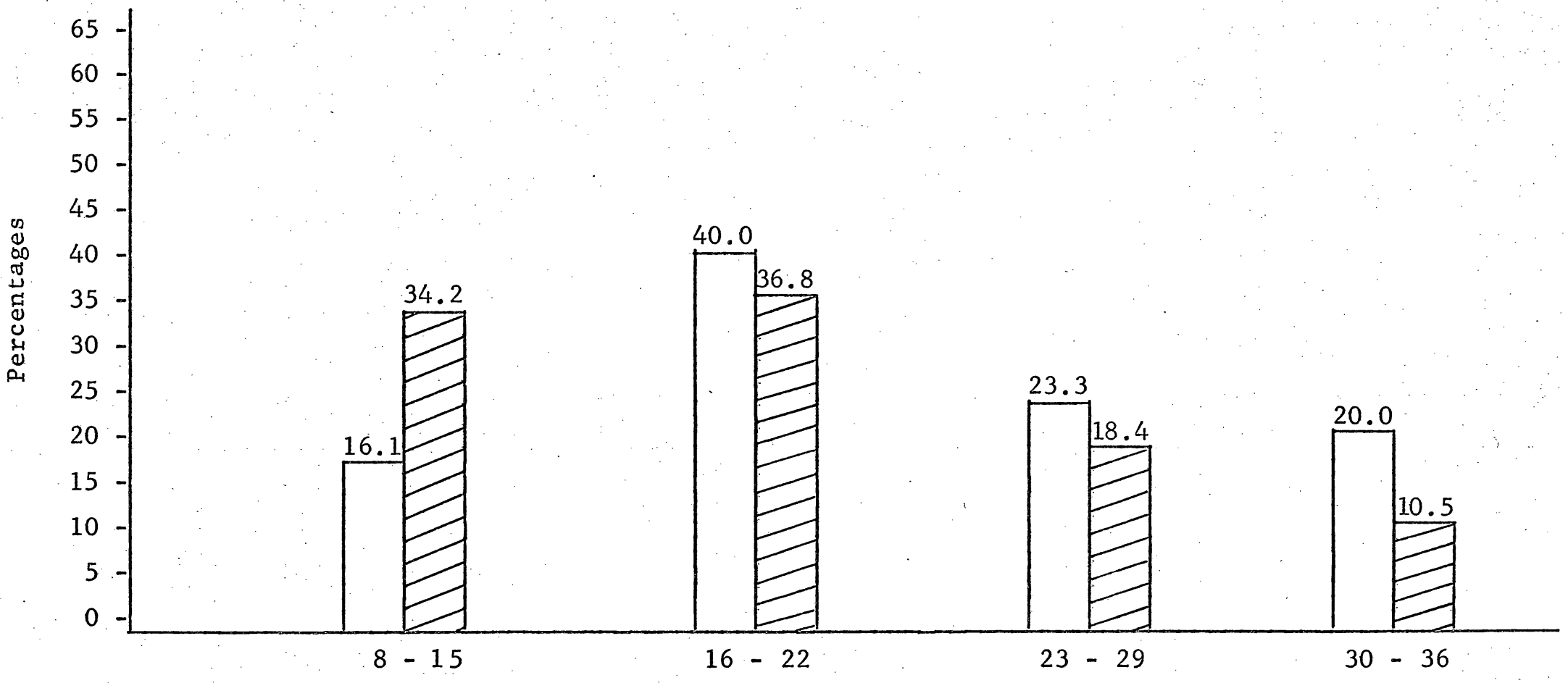

Scores 


\section{TABLE 4}

Differences in Originality Scores of Preschool Children by Sex and Ordinal Position

\begin{tabular}{|c|c|c|c|c|c|c|}
\hline & Ordinal Position & $\mathrm{N}$ & Mean & SD & $\begin{array}{c}\mathrm{U} \\
\text { value }\end{array}$ & $\mathrm{p}$ \\
\hline \multirow[t]{3}{*}{ Boys } & $(N=34)$ & & & & \multirow{3}{*}{104} & \\
\hline & oldest or $0 \mathrm{n} 1 \mathrm{y}$ & 15 & 22.40 & 8.40 & & \\
\hline & Later-born. & 19 & 19.11 & 7.32 & & \\
\hline \multirow[t]{3}{*}{ Girls } & $(N=34)$ & & & & & \\
\hline & oldest or only & 15 & 22.53 & 8.21 & \multirow{2}{*}{105.5} & \\
\hline & Later-born & 19 & 18.95 & 7.50 & & \\
\hline
\end{tabular}

(Mann-Whitney U, Siege1, S. Values of U, pp. 119-120.) 
later-born girls. However, the mean score of the oldest and only children regardless of sex was higher than the mean score of the laterborn children by approximately three points. When pictured graphically in Figure 2, the oldest and only boys and girls have a higher percentage of the most original scores of 23 through 36 than the later-born boys and girls. Later-born girls and boys have a higher percentage of the less original scores of 15 and below than first-born and only children. On the basis of these results Hypothesis 1 was rejected.

Hypothesis 2: There is no significant relationship between socioeconomic status and originality of preschool children. Lower-class and middle-class children will be equally original.

In order to test this hypothesis, the originality scores of these two groups were compared. As seen in Table 5, the total sample of middle-class children had a mean score of 23 and the total sample of lower-class children had a mean score of 17.7. The middle-class children on a whole scored approximately five points higher on the Originality Test than the lower-class children. This difference is statistically significant beyond the .004 level of confidence. On the basis of these results, the above hypothesis was rejected. This result shows that middle-class children are more original in their response than lowerclass children.

Figure 3 shows the frequency distribution of the scores comparing middle-class and lower-class scores. A fourth of the middle-class children had scores in the top quartile with scores ranging from 30 to 36, whereas only $3.1 \%$ or one child from the lower-class scored in this same range. Almost half of the 22 middle-class scores were 23 or above 
Figure 2

Distribution of Originality Scores by Sex and Ordinal Position
LB : 1ater-born boys
$\mathrm{OB}$ : oldest or on1y boys
LG: 1ater-born girls
OG: oldest or only girls

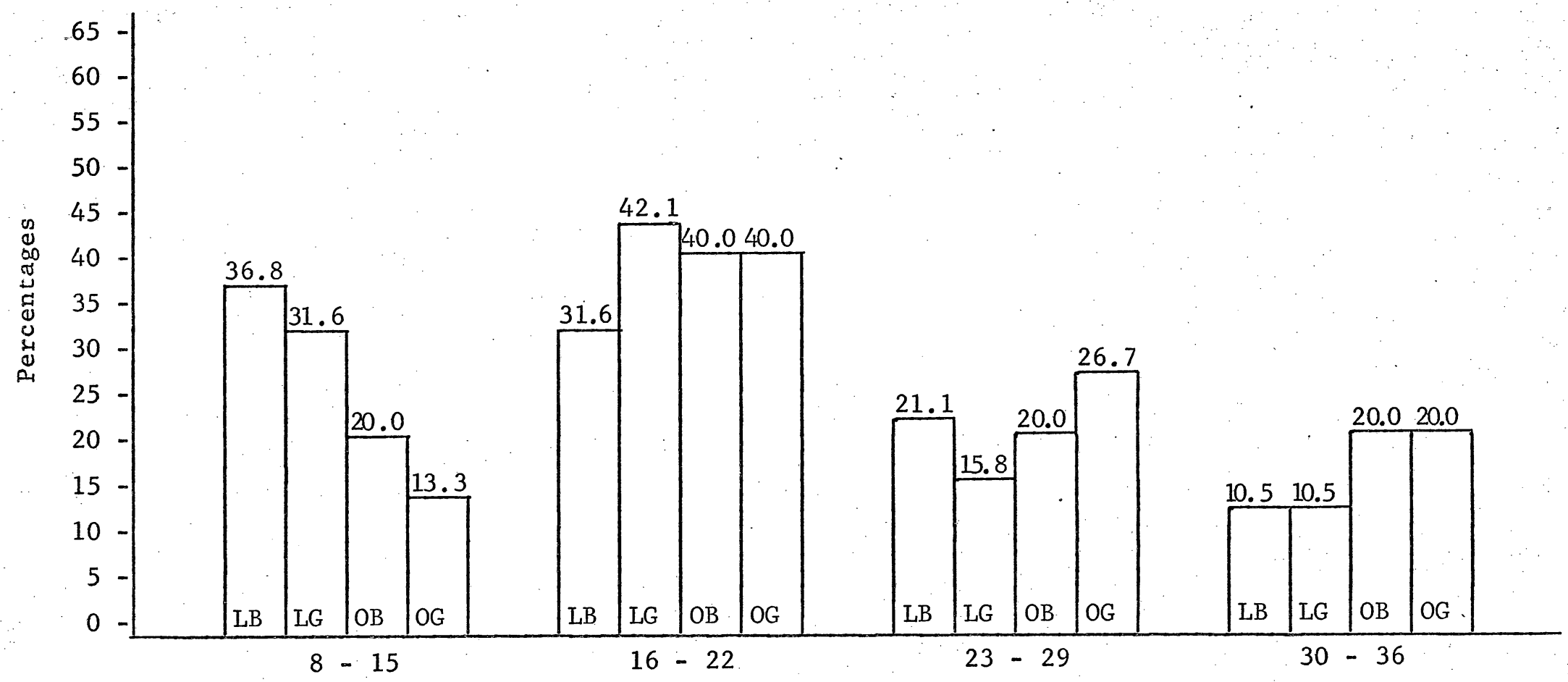

Scores 


\section{TABLE 5}

Differences in Originality Scores of Preschool Children by

Socioeconomic Status

\begin{tabular}{lccccc}
\hline & $\mathrm{N}$ & Mean & SD & $\mathrm{z}$ & $\mathrm{p}$ \\
\hline & & & & & \\
Middle Class & 36 & 23.08 & 8.25 & & \\
& & & & & \\
Lower Class & 32 & 17.69 & 6.30 & & \\
\hline
\end{tabular}


Figure 3

Distribution of Originality Scores by Socioeconomic Status

- Lower-Class children $(\mathrm{N}=32)$

- Middle-Class children $(\mathrm{N}=36)$

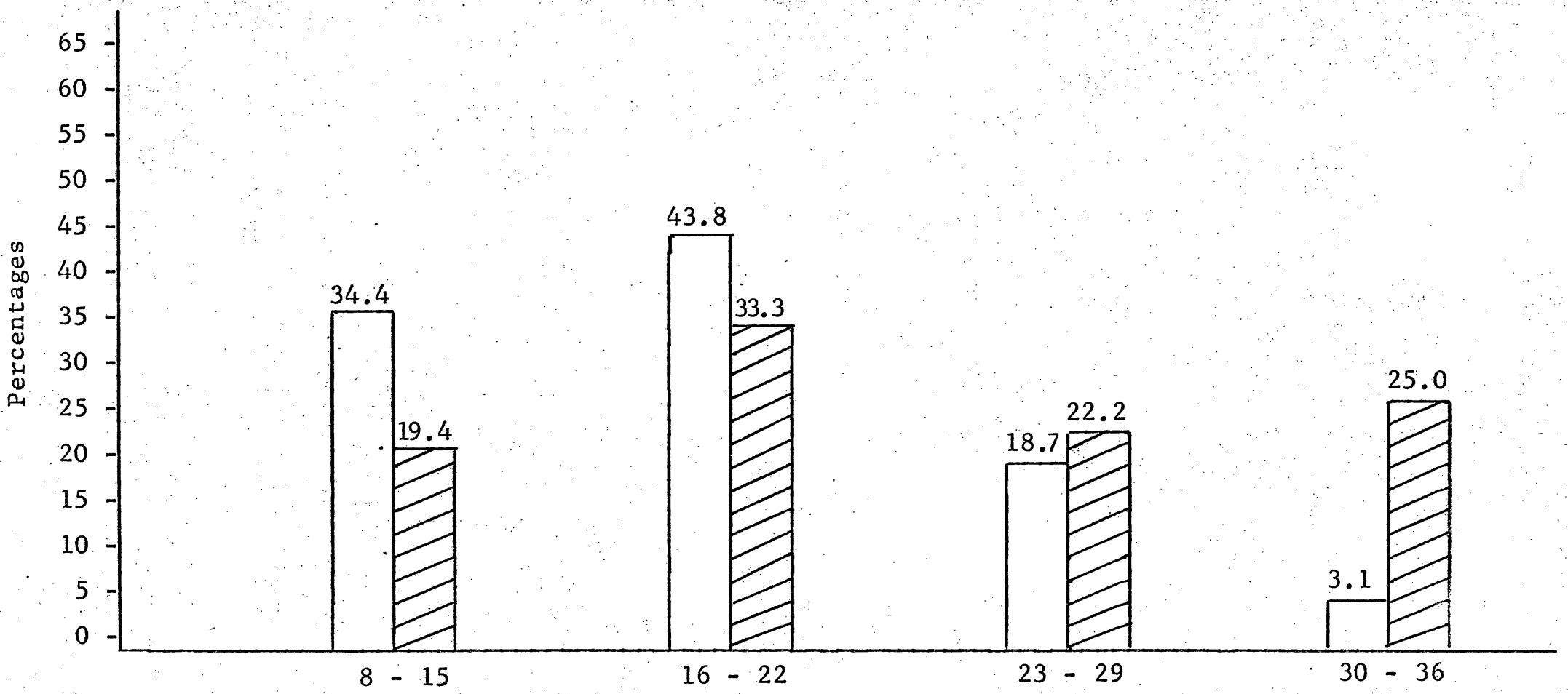

Scores 
compared with approximately $22 \%$ of the lower-class scores. Slightly over a third of the lower-class children, but less than one-fifth of the middle-class children had scores in the lowest quartile.

In analyzing the data further, the originality scores of middleclass boys were compared with those of lower-class boys, and the scores of middle-class girls were compared with those of lower-class girls. The results of these comparisons are presented in Table 6. A mean score difference of 6.1 between middle-class and lower-class boys was obtained which is statistically significant beyond the .05 confidence level. Although a mean score difference of 4.7 was obtained between middle-class and lower-class girls, this is not statistically significant. This indicates that middle-class boys are more original than lower-class boys, but that there is no significant difference between the originality of middle-class and lower-class girls. As shown graphically in Figure $4,27.8 \%$ of the middle-class girls but none of the lower-class girls scored in the highest percentile. Forty-five per cent of the girls and $50 \%$ of the boys from the middle-class scored above 22 , whereas on $1 y 25 \%$ of the girls and $19 \%$ of the boys from the lower-class scored in this same range.

Table 7 reports a comparison of the originality scores of the total sample of children by birth order and socioeconomic status. oldest and only middle-class and lower-class children were compared. Although there was a mean difference of 4.5 in the scores in favor of the middle-class children, this was not statistically significant. Comparing later-born children from the middle-class and lower-class, a mean difference of 5.4 was obtained in favor of the middle-class 
TABIE 6

Differences in Originality Scores of Preschool Children by Sex and Socioeconomic Status

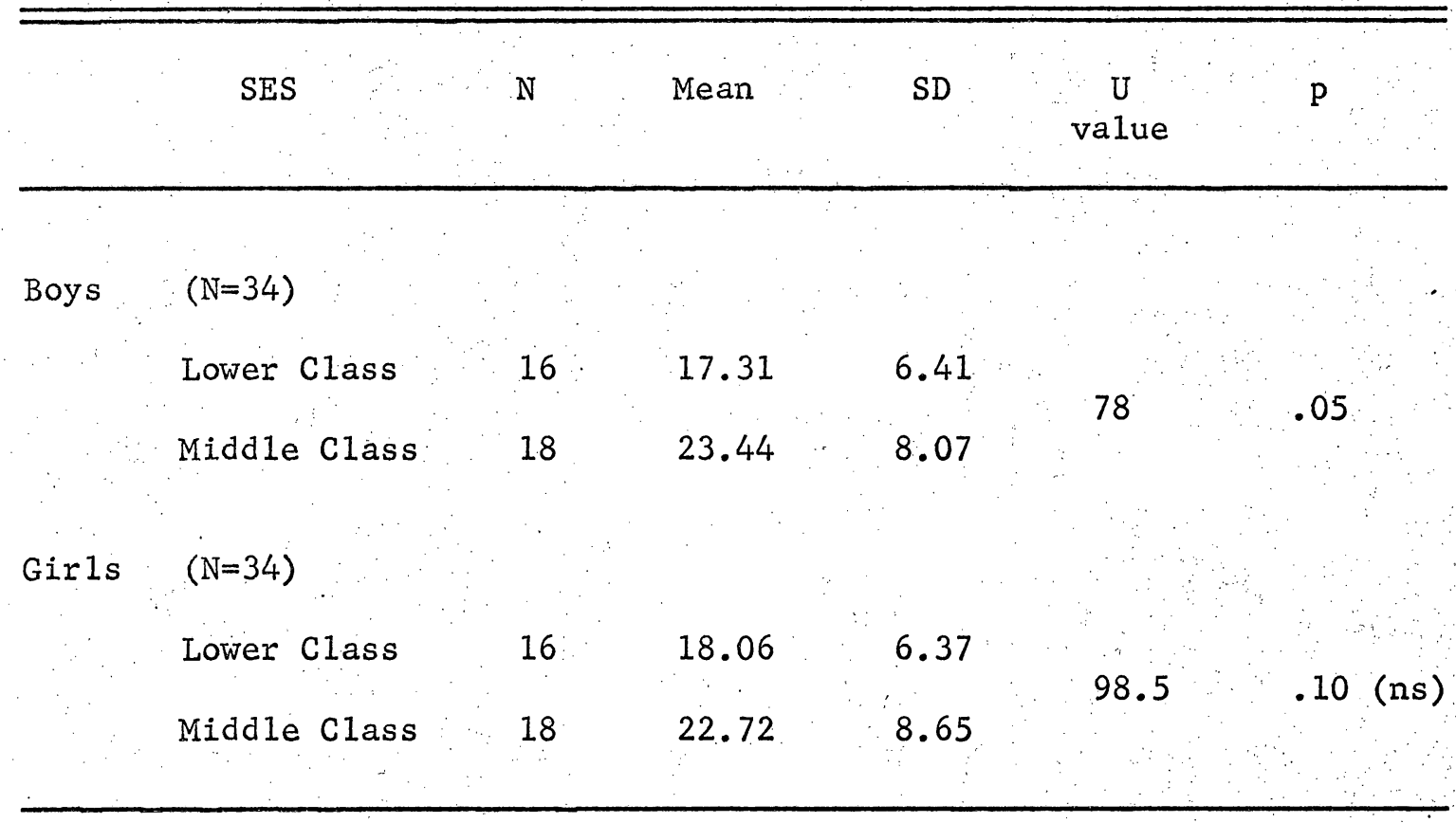


Figure 4

Distribution of Originality Scores by Sex and Socioeconomic Status

$\begin{array}{lll}\text { LB: Lower-class boy } & \text { MB: Middle-class boy } \\ \text { LG: Lower-class gir } 1 & \text { MG: Middle-class gir } 1\end{array}$

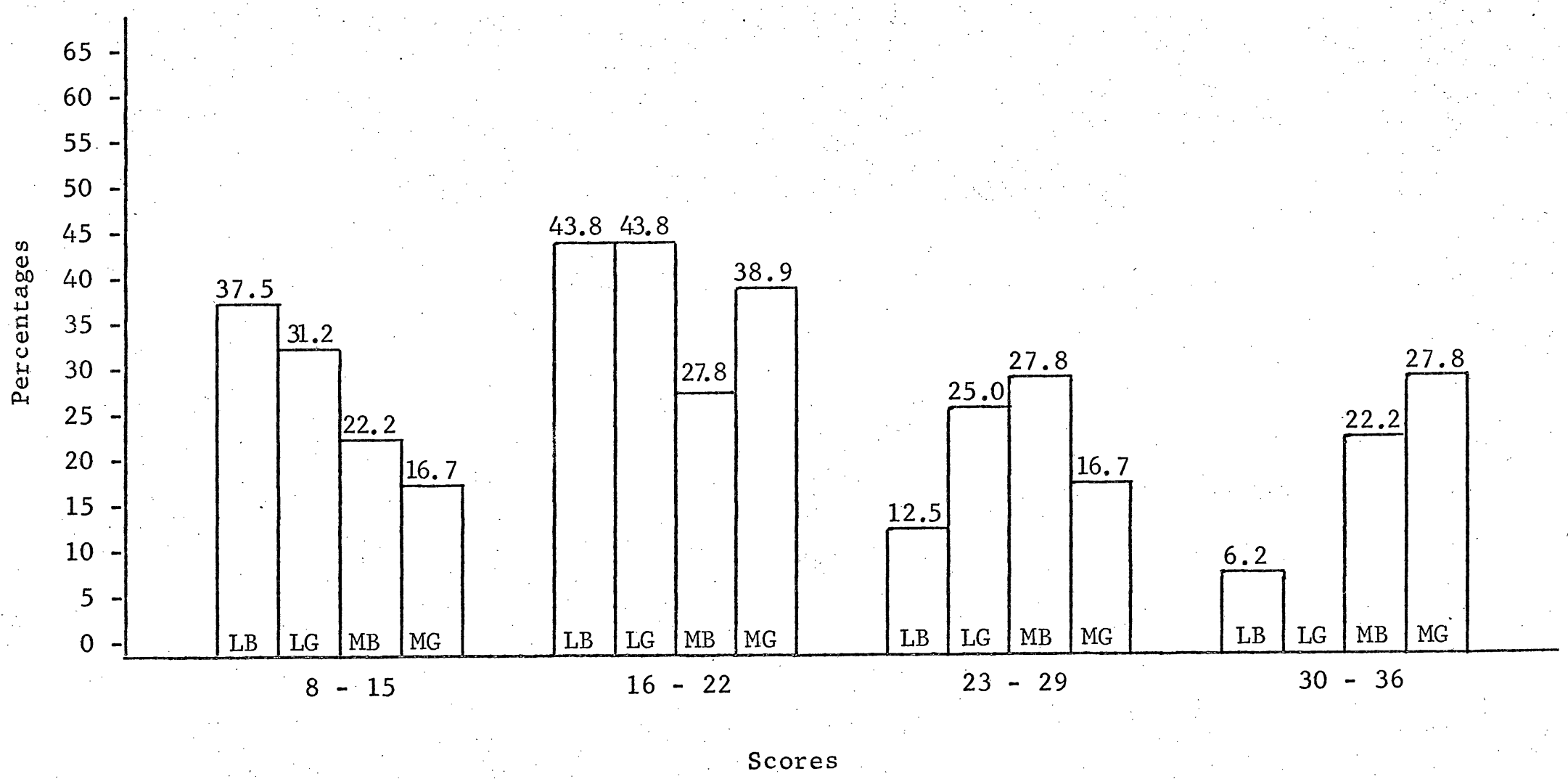




\section{TABLE 7}

Differences in Originality Scores of Preschool Children by Ordinal Position and Socioeconomic Status

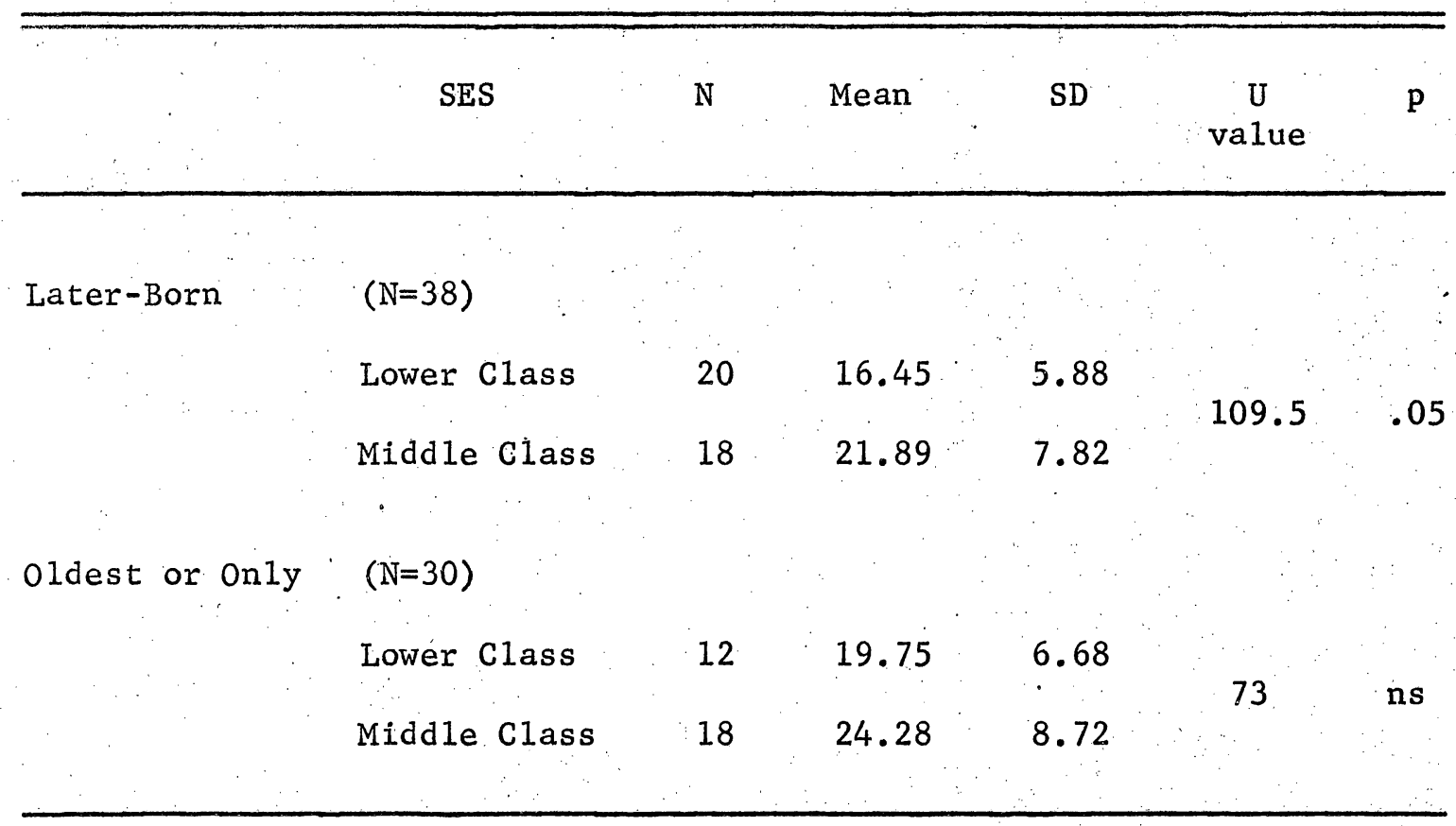


subjects. This difference was significant at the .05 level of confidence. The results indicate that there is a relationship between socioeconomic status and originality of later-born children but not between socioeconomic status and originality of first-born or only children. Later-born children from the middle-class appear to be more original than later-born children from the lower-class, whereas there is no significant difference in the originality of first-born or only children regardless of socioeconomic status. The oldest and only children from both the middle-class and the lower-class had a higher mean score than their later-born counterparts.

Another interesting finding shown in Table 7 is that laterborn children from the lower-class seem to be the least creative group in the entire sample, whereas oldest or only children from the middle-class appear to be the most original in the sample.

Figure 5 shows the comparison of birth order and socioeconomic status. Forty-five per cent of the lower-class later-born subjects had scores in the lowest quartile compared with only $16.7 \%$ of the lower-class oldest or only children. The majority of oldest or only children from the lower-class, 58\%, had scores between 16 and 22 . Fifty-six per cent of the oldest or only children from the middleclass compared with $39 \%$ of the later-born subjects from the middleclass had scores of 23 or above. A much higher proportion of both middle-class oldest or only children and later-born children, compared with their lower-class counterparts, had scores in the top quartile. 
Figure 5

Distribution of Originality Scores by Ordinal Position and Socioeconomic Status

LO: Lower-class oldest or on 1 y children

LL: Lower-class 1ater-born children
MO: Middle-class oldest or only children

ML: Middle-class 1ater-born children

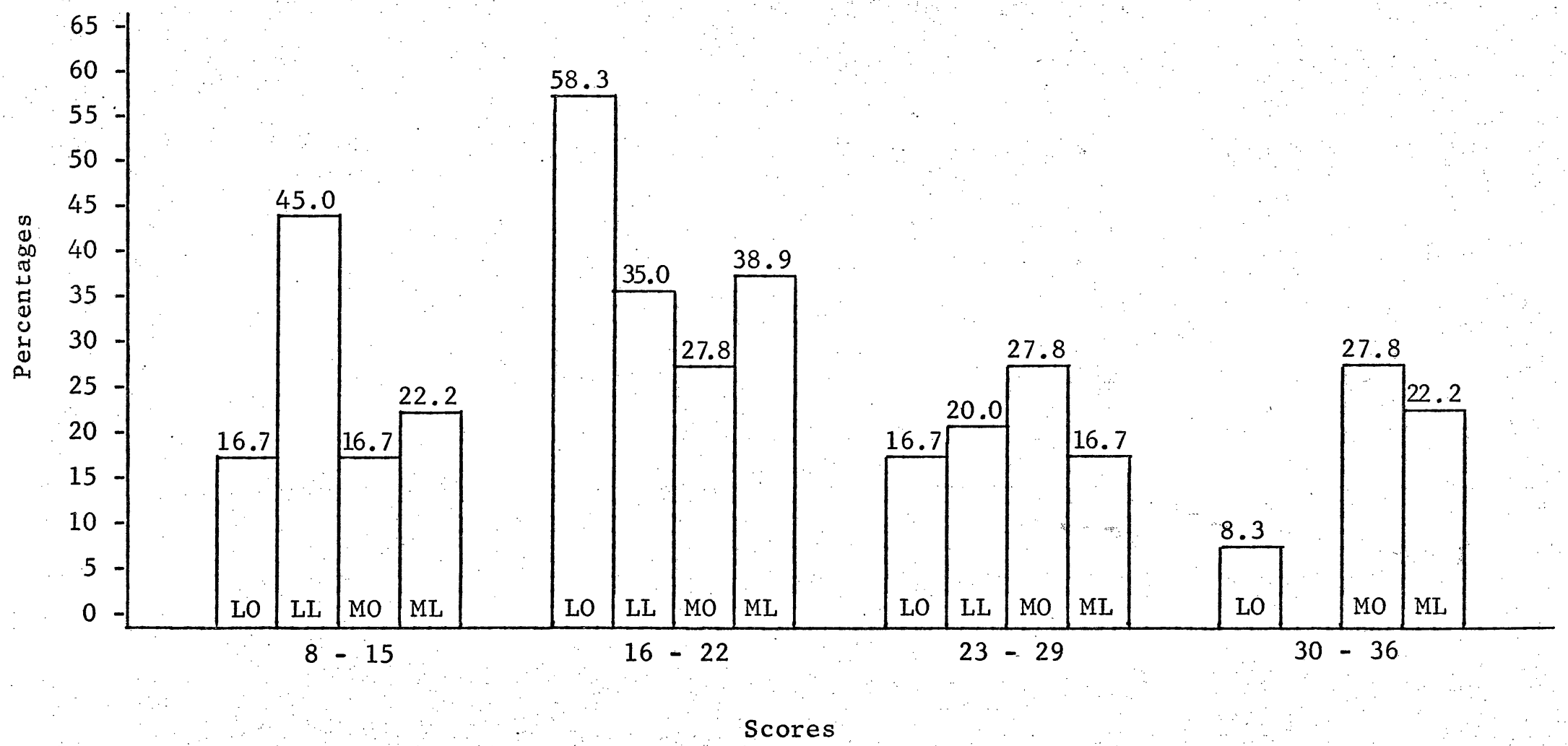




\section{Discussion}

The purpose of this study was to determine the relationship between creativity and socioeconomic status, and creativity and birth order of preschool children. Just one aspect of creativity, originality, was chosen for study. Null-hypotheses were that middle-class and lowerclass children would be equally original and that first-born or only children and later-born children would be equally original. The results of the data have not supported these nu11-hypotheses; therefore, both were rejected.

Middle-class children were found to be more creative than lowerclass children. This was significant at the .004 level of confidence as shown in Table 5. This finding was in the direction indirectly suggested by previous research that found middle-class parents to be more permissive in their treatment of infants and young children as well as more demanding of independence and achievement than lowerclass parents.

Middle-class boys were found to be more original than lower-class boys, but contrary to expectation, no significant difference was found between the originality of middle-class and lower-class girls. As seen in Table 6 , the mean score of the middle-class girls was $4 \frac{1}{2}$ points higher than that of the lower-class girls. This was approaching the .10 level of confidence but was not accepted as significant in this study. An explanation might be that in our society girls are protected, cuddled, and restricted more than boys who are encouraged to be independent, rough, and outgoing. Creativity seems to be 
fostered by independence and thus boys would have more of an advantage over girls.

The investigator believed that later-born children would be more original than first-born or only children. However, the results of this study indicate just the reverse to be true. First-born or only children were more original than later-born children. As seen in Table 3, this difference was significant at a confidence level of .04. Evidently, the fact that parents are usually more inexperienced, anxious, over-protective, and more restrictive and coercive with first-born and only children than with later-born children does not seem to hinder the development of creativity. Perhaps the first-born child is motivated to develop ideas and mental abilities at an early age because he is talked to more, played with more, and stimulated more, thus giving him an advantage over later-born siblings. There is a tendency for first-born children to score slightly higher in tests of verbal intelligence, especially at younger ages (Hoffman and Hoffman, 1966). The first-born in all probability receives a great deal more verbal stimulation from his parents than any later-born children (Lasko, 1954). It might be possible that this stimulation by the mother could also increase the first-born's creative ability. Another theoretical explanation could be that a first-born child feels threatened when dethroned by other siblings and consequently works harder to stay in the favored position of his parents by constantly striving to excel his brothers and sisters. Later-born children might conceivably look up to the oldest sibling and depend on him for ideas 
and support instead of relying on themselves. This dependency on older siblings would not be conducive to independent, divergent thinking believed to be involved in creativity.

The data indicate that socioeconomic status is related to the creativity of later-born children. As seen in Table 7, later-born children from the middle-class were significantly more original than those from the lower-class. This follows the trend suggested by Hypothesis 2 which found the total sample of middle-class children to be more original than the lower-class children. Waldrop and Bell (1964), in a study of the dependency needs of 44 preschool boys as related to family size and density, found indications,

... that after a mother has had more than the average number of children she tends to become unconcerned about the younger ones. This unconcern may make her unresponsive to the dependency demands made by a preschool child, and also less likely to protect the child from anxietyarousing situations ... It could be concluded from this that when a mother is not available to reward achievement or approval-seeking behavior the child is apt to become less independent and spend more time in support-seeking behavior.

Although the difference has declined in recent years, parents of low socioeconomic status tend to have more children, on the average, than parents of higher status (Jersild, 1968; Hoffman and Hoffman, 1966). Perhaps the lack of individual attention in large families makes laterborn children more dependent and less creative instead of more independent and creative. This could have affected the lower-class later-born children in this sample as most of them had four or more siblings. In fact, it was very difficult to.find first-born or only children from the lower-class, but there was an abundance of later-born children. 
It might be possible that the effects of deprivation traditionally associated with mother-child separation may also occur through insufficient interaction between mother and child when there are a large number of children in the family.

There was no significant diffexence in the originality scores of oldest or only children from the middle and lower classes. Although the mean score of the middle-class children, as seen in Table 7, was approximately $4 \frac{1}{2}$ points higher than that of the lower-class children, it was not significant in this study. Perhaps the extra attention and stimulation of the first-born child is universal regardless of socioeconomic status. The first-born child may be highly motivated, despite the class environment into which he was born, both by his parents and by an inner drive to remain first.

The fact that the lower-class children in this sample were all attending a nursery school, day care center, or kindergarten may have favorably influenced their originality scores. These children were enrolled in one of these programs for an average of eight months at the time of testing. It is quite conceivable that in this length of time certainly their basic knowledge and possibly their creative ability must have been broadened and stimulated. This may partially account for the lack of significant differences between originality scores of middle-class and lower-class girls and middle-class and lower-class oldest or only children.

\section{Limitations and Recommendations}

The present study was limited to a relatively small sample of middle-class and lower-class children. The sample of first-born or on 1 y 
lower-class children was especially limited because very few were enrolled in nursery schools, day care centers, and kindergartens in the area. Negroes and children of other nationalities were not included in the study as there were not enough of these children in the middle-class for comparison with those from the lower-class. Nonparametric statistics were employed in analyzing the data; therefore, the results cannot be generalized to the larger population. Findings of this study apply only to this sample of children.

Future research might profitably replicate this study using Negro preschool children in an effort to investigate the relationship of race to the development of creativity. A comparison of the creative ability of lower-class children enrolled in nursery school with that of those who have never been enrolled in a nursery school would also be beneficial. Another possible area of study would be a follow-up or longitudinal study of highly creative preschool children through the elementary grades in order to determine whether our educational system really does stifle creativity as has been suggested (Torrance, 1959; Getzels and Jackson, 1962). Another intriguing possibility would be to investigate why some lower-class preschool children are highly creative. Perhaps an in-depth study and comparison of the physical, social, and emotional home environments of highly creative and uncreative lower-class children would offer some clues. A comparison of parental child-rearing attitudes of these two groups of children might also prove beneficial. The same type of comparisons could also be made between highly creative and relatively uncreative middle-class children. Because few studies have been 
conducted involving creativity of preschool children, the possibilities for future research seem limitless. 


\section{CHAPTER V}

\section{SUMMARY}

The purpose of this research was to study the relationship of birth order and socioeconomic status to creativity of preschool children. The originality of lower-class children was compared with that of middle-class children, and the originality of first-born and only children was compared with that of later-born children.

An Originality Test developed by Starkweather ( $\left.n_{0} d_{0}\right)$ to study creativity of preschool children was individually administered to 68 preschool children enrolled in seven nursery schools, kindergartens, and day care centers in Southwestern Virginia. At the time of testing the children ranged in age from 4 years 1 month to 6 years 0 months with the average age being 5 years 2 months. On the basis of information obtained from school records, the children were classified by social class according to the McGuire-White Index of Social Status - Short Form, and by ordinal position.

A comparison of the originality scores of middle-class and lowerclass children revealed a significant difference. The middle-class children scored an average of five points higher than the lower-class children, a difference significant beyond the .004 level of confidence. In analyzing the scores by sex and socioeconomic status, middle-class boys were found to be more creative than lower-class boys; but there 
was no significant difference between middle-class and lower-class girls.

Contrary to expectation, a comparison of first-born and only children with later-born children revealed that first-born and only children were more original than later-born children. This difference was significant at the .04 level of confidence. In analyzing the data by ordinal position and socioeconomic status, oldest or only children were found to be equally creative regardless of socioeconomic class. No significant difference existed between first-born or only children in the middle and lower classes. On the other hand, later-born children from the middle-class were found to be significantly more original than those from the lower-class.

In this study birth order and socioeconomic status generally did appear to affect significantly the creativity of preschool children. Later-born children from the lower-class were found to be the least original with a mean score of 16.5 , and first-born and only children in the middle-class were found to be the most original with a mean score of 24.3 .

On the basis of this investigation, it appears that the life experiences related to social class position do affect the level of creativity achieved by children. The cultural and environmental enrichment of the middle-class child seems to foster creativity. The experiences related to birth order also appear to affect the development of creativity. The first-born or only position in the family constellation seems to enhance creativity. 
One important objective of research is to provide researchers and their associates with tools that expand their powers of prediction. From this study an estimate of a child's creativity can be predicted when his socioeconomic status and birth order are known. For example, a first-born child from the middle-class would likely be more creative than a later-born child from the lower-class. Perhaps with more research this predictive power would become more definitive and accurate.

Despite the finding that middle-class children were generally more creative than lower-class children, a puzzling discovery is that not all lower-class children were low in originality. In fact some lower-class children were exceptionally creative. Being born into the lower-socioeconomic status does not necessarily predispose lower-class children to low creativity. Perhaps a study of the home environments of these children would provide the answer to this puzzle.

Merely being in a preschool program does not help lower-class children catch up to their middle-class counterparts. The conscious development of creativity is not one of the goals of the majority of teachers. Most teachers are concerned with developing a child's social skills, I.Q., competence, attention span, academic skills and knowledge. Creativity seems to be a by-product of these other goals. It is common for teachers to expect children, beginning with elementary school, to conform to rather strict rules, regulations and routines and to consume a multitude of facts without proof or self-discovery. People are taught throughout their lives to think convergent $1 y$. Creativity is commonly believed to be a gift that an individual either 
has or does not have from birth. Divergent thinking is thought to be an exception rather than the rule.

One of the most important concerns at this stage of our knowledge is finding methods for the teaching of creativity. Perhaps a person can learn creativity just as he learns to spe11, or read, or write. It may we11 be that divergent thinking can be taught. However, the thought that creativity can be taught has not been given serious attention by most educators. An experimental program designed to increase creativity is needed to determine whether or not divergent thinking can be taught. Three matched groups of lower-class preschool children could be utilized in this effort: (1) a group receiving no preschool experience; (2) a group attending a regular preschool program; (3) an experimental group in a preschool program especially designed to increase creativity. Once the specific factors involved in the development of creativity have been isolated, these factors can be incorporated and adapted into teaching programs of all age levels and socioeconomic classes. Delving into the development of such a program is an exciting prospect for future research. 


\section{REFERENCES}

Adler, A. Understanding human nature. New York: Greenwood, 1927.

Adler, A. The pattern of life. New York: Cosmopolitan Book Corporation, 1930.

Asch, S. E. Studies of independence and conformity: I. A. minority of one against a unanimous majority. Psychological Monographs, 1956, 70 .

Barron, F. The disposition toward originality. Journal of Abnormal and Social Psychology, 1955, 51, 478-485.

Baumrind, Diana. Effects of authoritative parental control on child behavior. Child Development, 1966, 37, 887-907.

Bayley, Nancy and Schaefer, E. S. Relationships between socioeconomic variables and the behavior of mothers toward young children. The Journal of Genetic Psychology, 1960, 96, 61-77.

Becker, S. W. and Carroll, Jean. Ordinal position and conformity. Journal of Abnormal and Social Psychology, 1962, 65, 129-131.

Bing, Elizabeth. Effect of childrearing practices on development of differential cognitive abilities. Child Development, 1963, 34, 631-648.

Bossard, C. The creative child. Journal of Nursery Education, March $1962,17,55-57$.

Bronfenbrenner, $U$. Socialization and social class through time and space. In Eleanor E. Maccoby, L. M. Newcomb, and E. L. Hartely (Eds.), Readings in social psychology. New York: Holt, 1958, 400-425.

Cicirelli, V. G. Sibling constellation, creativity, I. Q., and academic achievement. Child Development, 1967, 38, 481-490.

Clausen, J. A., and Williams, Judith R. Sociological correlates of child behavior. In National Society for the Study of Education (Eds.), Sixty-second Yearbook. Chicago: University of Chicago Press, $1963,62-107$.

Dean, Daphne A. The relation of ordinal position to personality in young children. Unpublished M. A. thesis, State University of Iowa, 1947. 
Eiseman, R. Birth order and artistic creativity. Journal of Individual Psychology, 1964, 20, 183-185.

Eisner, W. Research in creativity: some findings and conceptions. Childhood Education, 1963, 39, 371-375.

Getzels, J. W. and Jackson, P. W. Family environment and cognitive style: a study of the sources of highly intelligent and highly creative adolescents. American Sociological Review, 1961, 26, 351-359.

Getzels, J. W. and Jackson, P. W. Creativity and intelligence: explorations with gifted students. New York: John Wiley and Sons, Inc., 1962.

Goodman, P. Compulsory mis-education. New York: Horizon, 1964.

Guilford, J. P. Creativity。 The American Psychologist, 1950, 5, 444-454.

Guilford, J. P. Creative abilities in the arts. Psychological Review, $1957,64,110-118$.

Guilford, J. P. Intellectual resources and their values as seen by scientists. In C. Taylor (Ed.), The 1959 University of Utah Research Conference on the Identification of Creative Scientific Talent. Salt Lake City: University of Utah Press, 1959, 128-149.

Guilford, J. P. Traits of Creativity. In H. Anderson (Ed.), Creativity and its cultivation. New York: Harper, 1959, 142-161 (b).

Hoffman, Lois W., and Hoffman, M. L. Review of child development research. Vo1. 2. New York: Russel1 Sage Foundation, 1966, 10-22.

Hurlock, Elizabeth B. Child development, 4th ed. New York McGrawHi11 Book Company, 1964.

Jersild, A. T. Child psychology, 6th ed. Englewood Cliffs, N. J: Prentice-Hall, Inc., 1968.

Koch, Helen L. Some personality correlates of sex, sibling position, and sex of sibling among five-and six-year old children. Genetic Psychology Monographs, 1955, 52, 3-50.

Kohn, M. Social class and the exercise of parental authority. American Sociological Review, $1959,24,352-366$.

Lasko, Joan K. Parent behavior toward first and second children. Genetic Psychology Monographs, $1954,49,97-137$. 
Lewis, Gertrude M. Releasing creativity. Childhood Education, 1965, $41,295-300$.

Lowenfeld, V. Current research on creativity. The Journal of the National Education Association, $1958,47,538-540$.

Macfarlene, J. W., Allen, L., and Honzik, M. P. A developmental study of the behavior problems of normal children between 21 months and 14 years. University of California Publications in Child Development. Vol. II. Berkeley, California: University California Press, 1954.

Maslow, A. H. Motivation and personality. New York: Harper, 1954.

McArthur, C. Personalities of first and second children. Psychiatry, $1956,19,47-54$.

McGuire, C. and White, G. D. The measurement of social status. Research paper: (mimeographed) The University of Texas, 1955.

Mukerji, Rose. Roots in early childhood for continuous learning. Childhood Education, 1965, 42, 28-34.

Nei11, A. S. Summerhi11. New York: Hart, 1964.

Nichols, R. C. Parental attitudes of mothers of intelligent adolescents and creativity of their children. Child Development, 1964, 35, 1041-1049.

Prothro, E. T. Socialization and social class in a transitional society. Child Development, $1966,37,219-228$.

Rogers, C. A therapist's view of personal goals. Pendle Hil1 Pamphlet 108. Wallingford, Pa: Pendle Hill, 1960.

Rosen, B. C. Social class and the child's perception of the parent. Child Development, 1964, 35, 1147-1153.

Sampson, E. E. Birth order, need achievement, and conformity. Journal of Abnormal and Social Psychology, 1962, 64, 155-159.

Schacter, S. The psychology of affiliation. Stanford, California: Stanford University Press, 1959.

Sears, P. S. Do11 play aggression in normal young children: influence of sex, age, sibling status, father's absence. Psychological Monographs, 1951,65 .

Sears, R. R. Ordinal position in the family as a psychological variable. American Sociological Review, 1950, 15, 397-401. 
Sears, R. R., Maccoby, E. E., and Levin, H. Patterns of child rearing. Evanston, Illinois: Row, Peterson, 1957.

Siegel, S. Nonparametric statistics for the behavioral sciences. New York: McGraw-Hil1 Book Company, Inc., 1956.

Smith, R. M. The relationship of creativity to social class. Exceptional Children, 1965, 31, 489-490.

Starkweather, Elizabeth $\mathrm{K}$. Problems in the measurement of creativity in pre-school children. Journal of Educational Measurement, 1964 , 1 , 109-113.

Starkweather, Elizabeth $\mathrm{K}$. Behind the scenes with creativity research. Alumnae Educators, Apri1 1965, 18-19.

Starkweather, Elizabeth $\mathrm{K}$. An originality test for preschool children. Oklahoma State University, Stillwater. Mimeographed. Undated.

Stout, A. M. Parent behavior toward children of differing ordinal position and sibling status. Unpublished doctoral dissertation, University of California, Berkeley, 1960 .

Taylor, C. W. A tentative description of the creative individual. Human Variability and Learning. Washington D. C.: Assoc. for Supervision and Curriculum Development, a department of the National Education Association, 1961, 62-79.

Taylor, C. W. and Holland, J. I. Development and application of tests of creativity. Review of Educational Research, 1962, 32, 91-102.

Torrance, E. P. Explorations in creative thinking in the early school years: a progress report. The Third University of Utah Research Conference on the Identification of Creative Scientific Talent. (Edited by C. W. Taylor.) Salt Lake City: University of Utah Press, 1959, 58-71.

Waldrop, Mary F. and Bell, R. Q. Relation of preschool dependency behavior to family size and density. Child Development, 1964, 35, 1187-1195.

Waters, Elinor and Crandall, V. J. Social class and observed maternal behavior from 1940 to 1960 . Child Development, 1964, 35, 1021-1032.

Werner, Emmy E. Changing concepts of intelligence and creativity. The Journal of Nursery Education, 1964, 19, 164-168.

Yamanwto, K. Creative thinking: some thoughts on research. Exceptional Children, $1964,30,403-410$. 
APPENDIX 
AN ORIGINALITY TEST FOR PRESCHOOL CHILDREN

\author{
developed by \\ Elizabeth K. Starkweather \\ Oklahoma State University \\ Stillwater, Oklahoma
}

\title{
Recommended Age Range
}

Approximately 3 years 6 months to 6 years 6 months.

The originality test depends on the child's ability to communicate verbally, and therefore, it should only be administered to children who are able to give at least four different ideas during the pretest or warm-up session.

older children obtain higher originality scores than younger children... When the test is administered to older children (e.g., seven year olds), it cannot identify the more original children inasmuch as the median score for such a group is apt to be near the ceiling of the test.

\section{Pretest or Warm-up Session}

Six white styrofoam pieces, each a different shape, are placed on the table before the child. The child is encouraged to manipulate them and to talk about them. He may be asked a question such as, "Do you see a piece that looks like something?" When the child responds, the experimenter agrees with his comment, whatever it is, and encourages him to talk about another piece. If the child does not respond, the experimenter picks up the rectangular piece and asks, "What could this be?" If the child still does not respond, the experimenter makes a suggestion in the form of a question, e.g., "Do you think it could be a window?" The experimenter may then move this piece a little to one side, if necessary, in order to focus the child's attention on the other pieces.

If the child gives the same response for different pieces, his response is accepted, but he is asked to think of something else that the piece might be. For example, if the child said that two different pieces could be a door, the experimenter would accept his response and at the same time encourage him to think of something different. "Yes, it certainly could be a door, but we already have one door. Can you think of something else that it could be?"

After the child has responded to the six forms, the expeximenter praises him by saying, "Good, you thought of something different for all these." In this way, during the warm-up session, the experimenter encourages the 
child to think of different responses for the various forms. (During the test proper, the child's responses are accepted without question even though he may repeat the same idea several times.)

\section{Originality Test}

The originality test is administered by showing the child one pair of identically shaped styrofoam pieces at a time. When he is shown the first pair, he is given his choice of the color he prefers. (The colors in Form-A are red and blue; and the colors in Form-B are green and yellow.) The color the child chooses is then placed on the table before him and the other is placed in front of the experimenter. The child is then asked what his piece could be or what it could be made into. After he responds, he is asked what the experimenter's piece could be. For the first pair, and occasionally during the remainder of the test, the experimenter includes the child's response in his next question. "If yours is a (caboose), then what could mine be?" Approval of each response is given by saying something such as, "Al1 right," or "It certainly could be." Whether or not a child gives different responses for the various shapes, his efforts are approved in the same manner.

When all ten pair of styrofoam forms have been shown to the child, the entire set is again presented. This time the child is given the other color, i.e., the one he had not chosen when they were first presented. During this second administration, each piece is placed before the child in an alternate position, e.g., sideways or up-side-down.

\section{$\underline{\text { Scoring }}$}

The combination of the two administrations of the research instrument offers four opportunities for a child to respond to each form, making a total of 40 responses. Each child's score is a numerical count of the number of different responses he gives. The responses are scored in the order in which the child has given them, and credit is given for each response which is different from all previous responses. Credit is given for objects which might be in the same category, such as a golf ball and a basebal1. Credit is not given for an object which is named a second time and altered only by a minor adjective, such as a ball and a big ball. No credit is given for a play on words, such as kigless, pigless, and sigless.

Occasionally children respond by naming objects which they can see in the room. This is noted on the score sheet, and in these instances, credit is given only if the experimenter can see some relationship between the responses and the styrofoam form which the child is holding.

No norms have been developed for the Originality Test, nor will they be developed. The value of the test lies in its ability to identify the 
more original and the less original children within a given group and to compare different groups of children, e.g., age groups, cultural groups, etc.

\section{Evaluation of the Originality Test}

Inter-judge reliability in scoring was determined by a comparison of two sets of scores. (1) The responses of individual children were scored jointly by two judges who participated in the development of the test; and (2) the same responses were scored by another person, trained in child development, but who had no experience with the test and who had no instructions other than the written directions for scoring. The coefficient of correlation (Pearson product-moment) between the two sets of judges' scores was +0.989 , significant beyond the .01 level. In view of these findings, the directions for scoring were accepted as adequate. Their use should assure reliable scoring.

The internal consistency of the instrument was demonstrated by means of a split-half correlation (Spearman-Brown formula). A coefficient of . $+0.932(p<.01)$ indicated that the test was reliable.

The validity of the instrument was demonstrated by comparing teachers' judgments with children's scores. Each child who scored high in originality was paired with each child who scored low, and teachers were then asked to indicate the child who was the more original in each pair. Teachers.' judgments were in the direction of the originality scores in 106 pairs out of a total of 153. A Chi-square analysis indicated this extent of agreement to be statistically significant. $\left(\mathrm{X}^{2}=22.752 ; \mathrm{p}(.001)\right.$

Test results indicate age differences in originality, but not sex differences. In a group of 80 children ranging in age from 3 years 6 months to 5 years 11 months, the older children earned the higher scores in originality. $\left(\mathrm{X}^{2}=17.39 ; \mathrm{p}<.01\right)$

Forms $A$ and $B$ of the originality test and the Peabody Picture Vocabulary test were administered to 18 children ranging in age from 3 years 4 months to 5 years 11 months. Half of these children were given the originality tests in an $A-B$ sequence and the other half in a B-A sequence. A comparison of the scores obtained on the originality tests indicated that the two forms, $A$ and $B$, were comparable. The product-moment correlation coefficient for the scores obtained on the two forms was $+0.904(p<.01)$, and for the scores obtained on the first and second tests was $+0.892(\mathrm{p}<.01)$.

The originality test requires verbal responses; nevertheless, the originality scores are independent of verbal ability. This was demonstrated by a correlation of the PPVT scores (verbal ability) and the originality scores. The product-moment correlation coefficients for 
these two sets of scores were t0.192 for Form-A and +0.162 for Form-B, neither of which was statistically significant. 
$-61-$

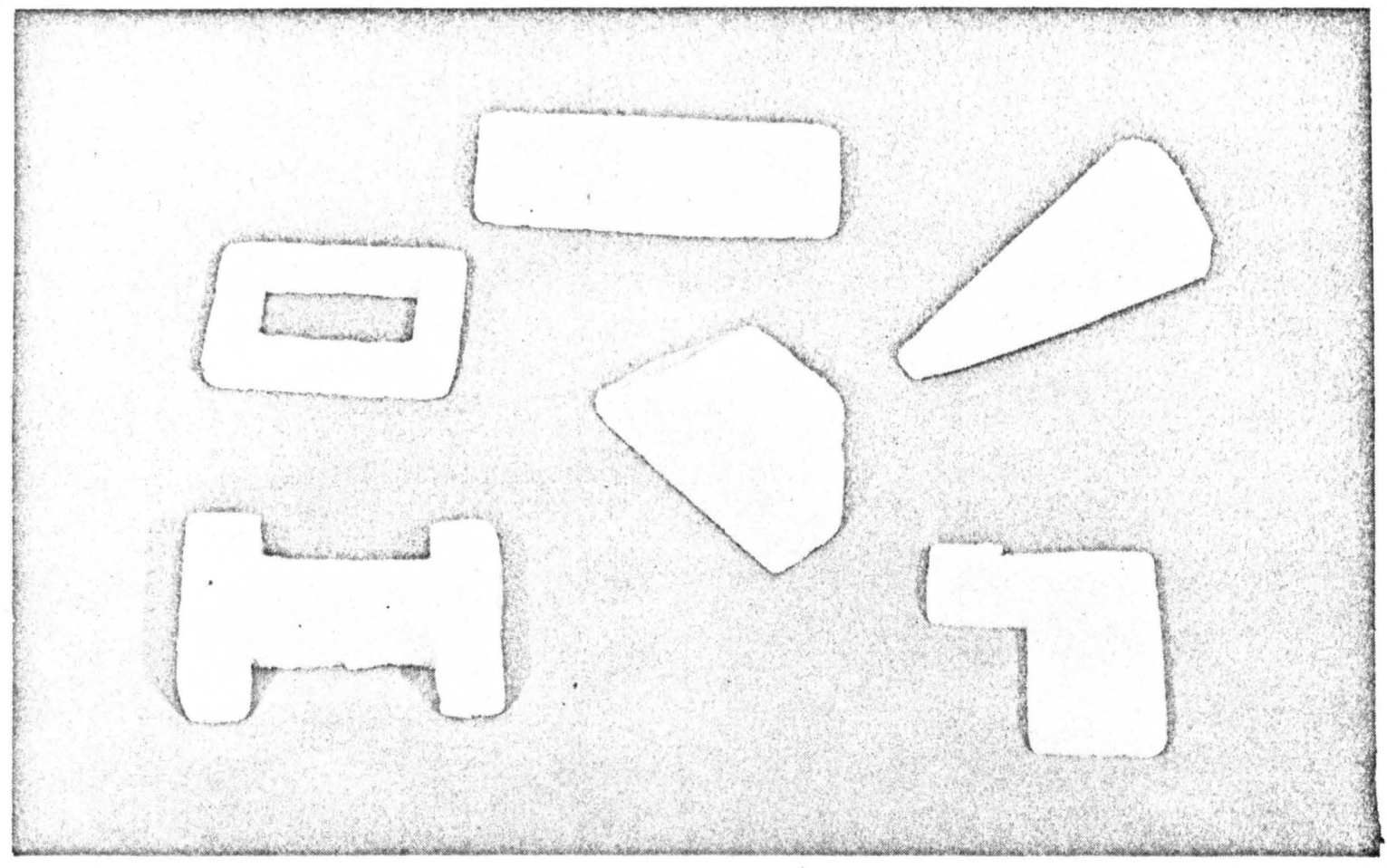

Figure 1. Forms used in the Warm-Up Session

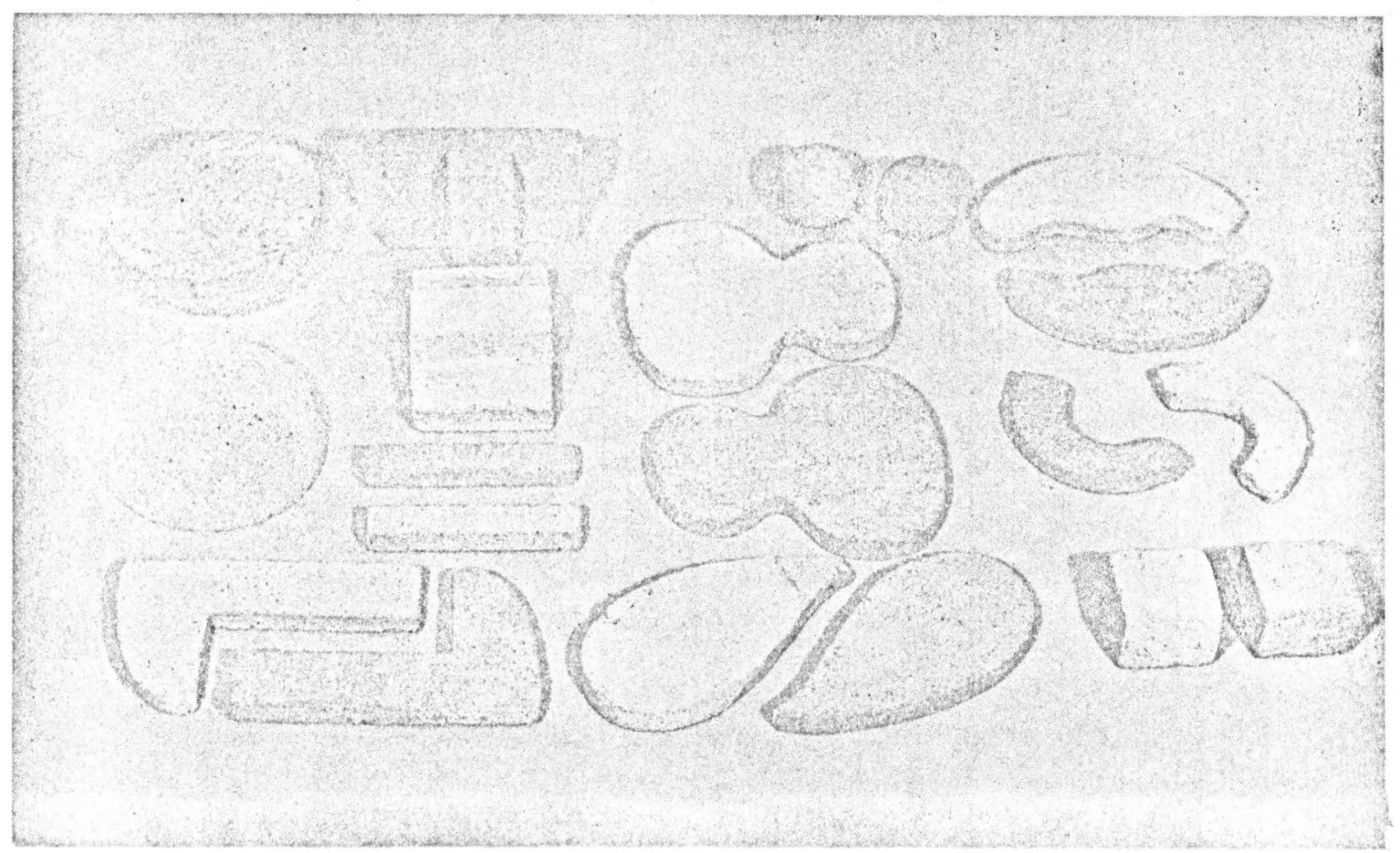

Figure 2. Forms used in the Research Instrument 


\section{DIRECTIONS FOR SCORING ORIGINALITY TEST}

A. Score the responses in the order in which the child gave them, columns $A$ and $B$ together and then columns $C$ and $D$ together. $1 A-1 B-2 A-2 B-3 A-3 B$, etc.

B. Mark each response either + for credit or - for no credit. Mark a response + if it is different from all previous responses. When in doubt, give the child credit.

\section{Categories of objects}

1. A child may name objects which are similar in category. The child receives credit for each different type of object in the category.

Ex: golf ball (+), baseball (t), moth ball (+)

2. A child may name the category and then name a specific object in the category.

Ex: bal1 $(t)$, rubber ball $(t)$, basebal1 $(t)$

\section{Examples of no credit}

1. A child does not receive credit when he combines two previous responses for which he has received credit.

Ex: tree $(+)$, cookie $(+)$, tree cookie (-)

2. A child does not receive credit when he names an object a second time altering it with a minor adjective.

Ex: ball (+), big ball (-), half ball (-)

Ex: duck $(+)$, part of a duck $(-)$

Ex: egg $(+)$, round egg $(-)$, cracked egg $(-)$

Ex: red ball (+), blue ball (-)

3. The child receives no credit for a play on words.

Ex: Kigless (-), Pigless (-), Sigless (-)

Ex: Rigco (-), Sig-co (-)

E. Some children look about the room for ideas. This is noted on the score sheet. For such responses, the child receives credit if there is a possible relationship between the response and the test form. 
Name Child 2

sex $M$

Date of Birth $4-16-60$

Age $3-7$

SPLIT-HALF SCORES

Code 2

Date $2-4-63$

odd $A B+$ even $C D=4$
Odd $C D+$ even $A B=5$

TOTAL

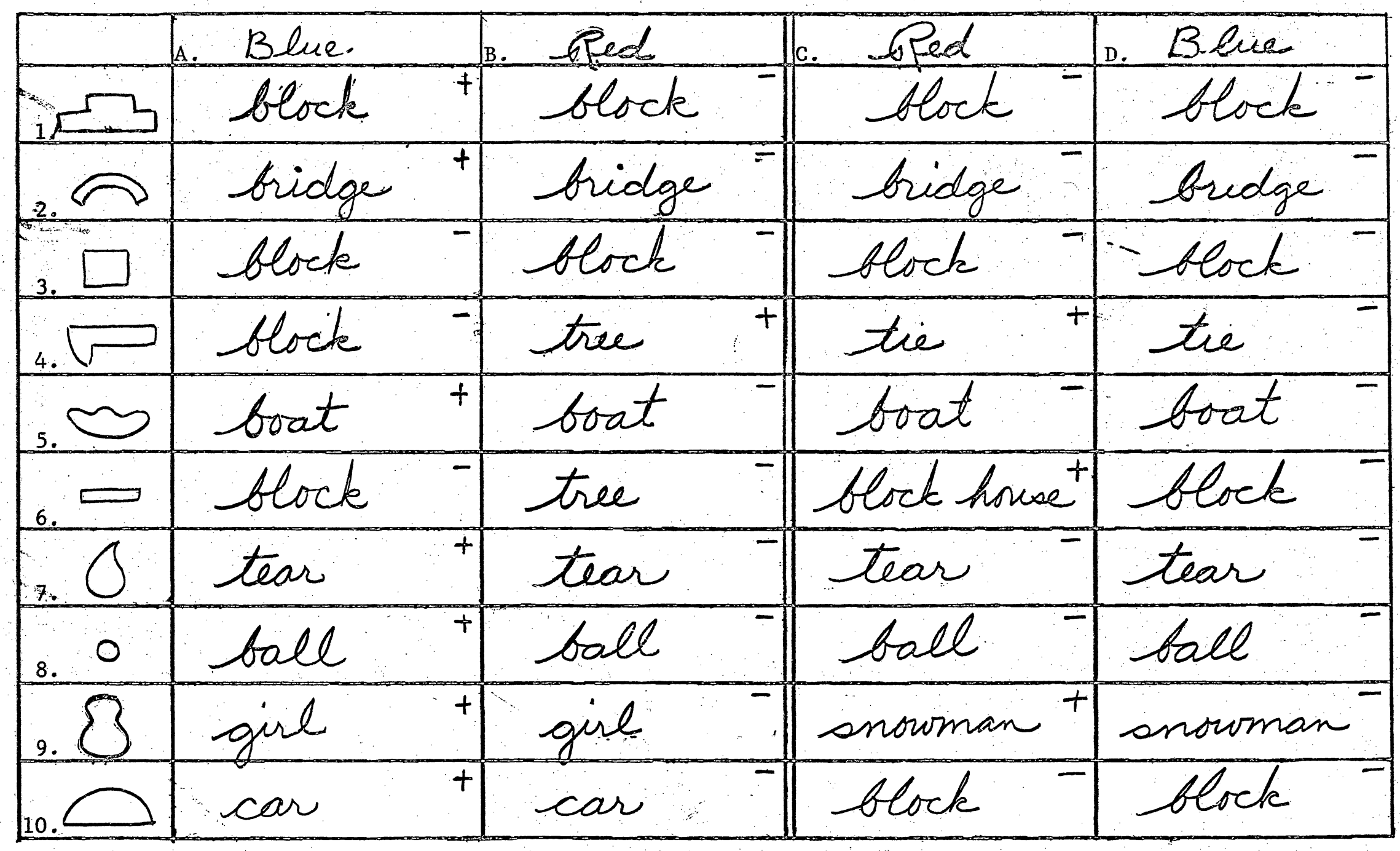


Name Child 317

Date of Birth $12-11-57$ Code 317 sex $F$

Age $5-11$

Date $12-6-63$
SFLIT-HAXP SCORES

odd $A B+$ ever $C D=15$

odd $C D+$ even $A B=18$

33

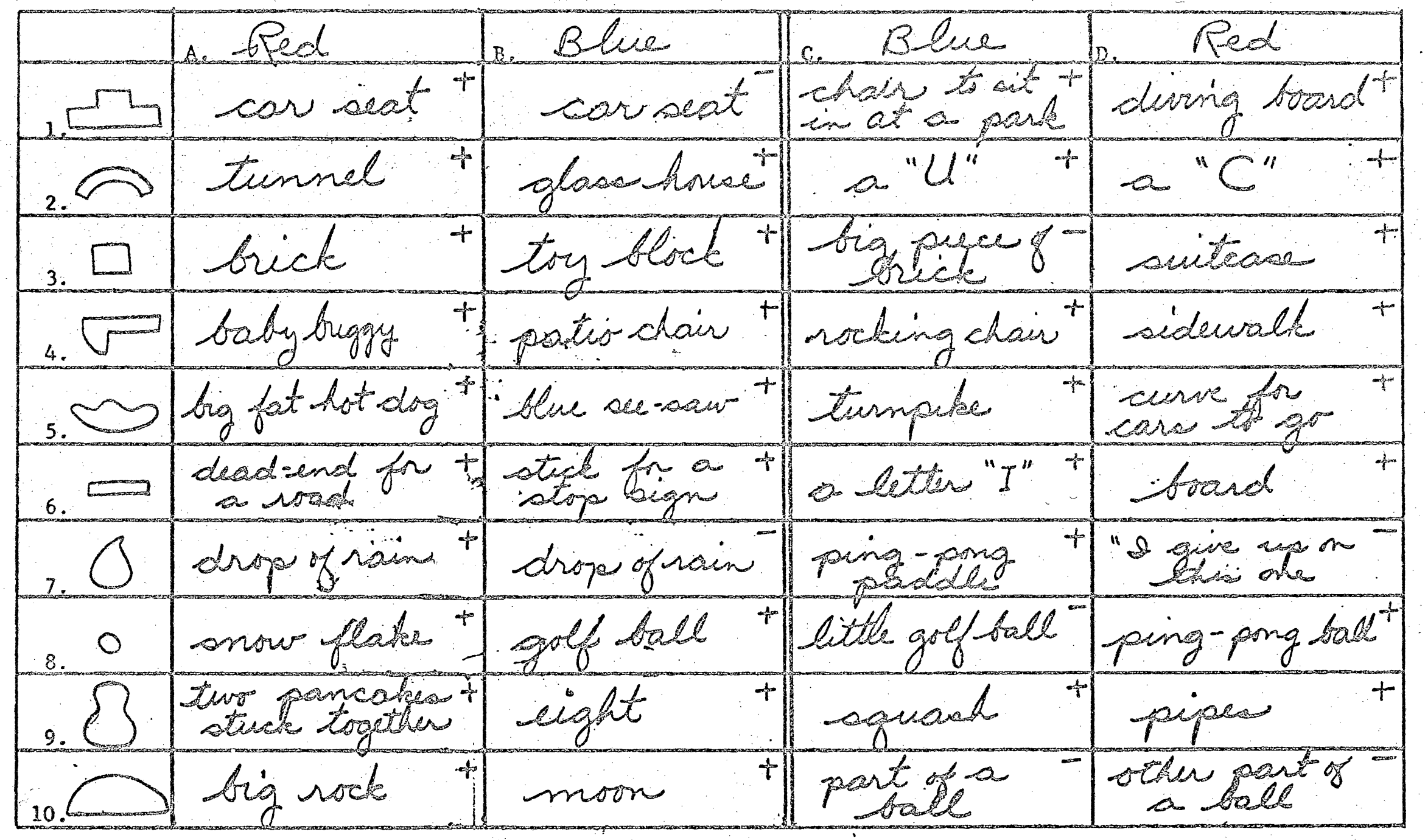




\section{The vita has been removed from the scanned document}


THE RELATIONSHIP OF BIRTH ORDER AND SOCIOECONOMIC STATUS

TO THE CREATIVITY OF PRESCHOOL CHILDREN

by

Joanne Sally Lichtenwalner

ABSTRACT

The creativity of 68 middle- and lower-class Caucasian preschool children attending a nursery school, kindergarten, or day-care center in Southwestern Virginia was measured by an object-identification origi- . nality test developed by Elizabeth $\mathrm{K}$. Starkweather at the Oklahoma State University. Each child was tested individually by the investigator in an isolated room or special testing room. The Mann-Whitney U Test was employed to analyze differences, with a confidence level of .05. First born and only children were significantly more creative than later-born children. Middle-class children were significantly more creative than lower-class children. It was concluded that enrollment in a preschool program alone is not sufficient to increase the creativity of lowerclass children to the level of their middle-class peers. It was also pointed out that some lower-class children were exceptionally creative and that further research into the home environments of these preschoolers might provide the answer to this puzzle. Experimental programs designed to increase creativity are needed to determine whether or not divergent thinking can be taught. 